\title{
DARPP-32, jack of all trades... master of which?
}

\author{
Marion Yger ${ }^{1,2,3}$ and Jean-Antoine Girault ${ }^{1,2,3}$ * \\ 1 INSERM UMR-S 839, Paris, France \\ 2 Université Pierre et Marie Curie, Paris, France \\ ${ }^{3}$ Institut du Fer à Moulin, Paris, France
}

Edited by:

Riccardo Brambilla, San Raffaele

Scientific Institute and University, Italy

Reviewed by:

Rosario Moratalla, Cajal Institute,

Consejo Superior de Investigaciones

Cientificas, Spain

Serge N. Schiffmann, Université Libre

de Bruxelles, Belgium

\section{*Correspondence:}

Jean-Antoine Girault, INSERM UMR-S 839, Institut du Fer à Moulin,

Université Pierre et Marie Curie, 17

rue du Fer à Moulin, 75005 Paris,

France.

e-mail: jean-antoine.girault@inserm.fr
DARPP-32 (PPP1R1B) was discovered as a substrate of cAMP-dependent protein kinase (PKA) enriched in dopamine-innervated brain areas. It is one of three related, PKA-regulated inhibitors of protein phosphatase-1 (PP1). These inhibitors seem to have appeared in early vertebrate ancestors, possibly Gnathostomes. DARPP-32 has additional important biochemical properties including inhibition of PKA when phosphorylated by Cdk5 and regulation by casein kinases 1 and 2. It is highly enriched in specific neuronal populations, especially striatal medium-size spiny neurons. As PP1 inhibitor DARPP-32 amplifies and/or mediates many actions of PKA at the plasma membrane and in the cytoplasm, with a broad spectrum of potential targets and functions. DARPP-32 also undergoes a continuous and tightly regulated cytonuclear shuttling. This trafficking is controlled by phosphorylation of Ser-97, which is necessary for nuclear export. When phosphorylated on Thr-34 and dephosphorylated on Ser-97, DARPP-32 can inhibit PP1 in the nucleus and modulate signaling pathways involved in the regulation of chromatin response. Recent work with multiple transgenic and knockout mutant mice has allowed the dissection of DARPP-32 function in striato-nigral and striato-pallidal neurons. It is implicated in the action of therapeutic and abused psychoactive drugs, in prefrontal cortex function, and in sexual behavior. However, the contribution of DARPP-32 in human behavior remains poorly understood. Post-mortem studies in humans suggest possible alterations of DARPP-32 levels in schizophrenia and bipolar disorder. Genetic studies have revealed a polymorphism with possible association with psychological and psychopathological traits. In addition, a short isoform of DARPP-32, t-DARPP, plays a role in cancer, indicating additional signaling properties. Thus, DARPP-32 is a non-essential but tightly regulated signaling hub molecule which may improve the general performance of the neuronal circuits in which it is expressed.

Keywords: dopamine, glutamate, cAMP, protein-phosphatase 1, CDK5, behavior, addiction, Parkinson's disease
What we know today about signal transduction derives from early studies of the glycogen metabolism. Sutherland (1972) identified cAMP as the intracellular second messenger which mediates the action of glucagon and epinephrine on glycogen degradation through activation of glycogen phosphorylase. Edwin G. Krebs and Edmond H. Fischer identified the role of the first protein kinase (PKA), phosphorylase kinase, in activating phosphorylase (see Fischer, 1997). In 1968, Krebs and Walsh discovered that cAMP action was mediated by activation of cAMP-dependent PKA, which activated phosphorylase kinase (Walsh et al., 1968). Paul Greengard and his collaborators then showed that similar cascades of biochemical reactions were critical in the action of neurotransmitters in the nervous system (Nestler and Greengard, 1983; Greengard, 2001). They identified the first dopamine (DA) receptor by its positive coupling to adenylyl-cyclase (Kebabian et al., 1972) and downstream protein phosphorylation (Krueger et al., 1975). To better characterize the mode of action of neurotransmitters in various brain regions, Walaas et al. (1983b) undertook a systematic regional study of proteins phosphorylated by second messengers-activated protein kinases. Some of these substrates, or "third messengers" were evenly distributed whereas others were highly enriched in specific brain regions. For example, Walaas observed the enrichment of a $32-\mathrm{kDa}$ soluble PKA substrate in striatal slices extracts. The phosphorylation of this protein highly expressed in DA-innervated brain regions, was regulated by DA and cAMP and it was termed DARPP-32 (dopamine and cAMP-regulated phospho-protein Mr 32,000; Walaas et al., 1983a). DARPP-32 had properties similar to those of protein phosphatase1 (PP1) inhibitor-1 and was shown to be a potent inhibitor of PP1 when phosphorylated by PKA (Hemmings et al., 1984a). Hence, DARPP-32 is also known as phospho-protein phosphatase-1 regulatory subunit 1B (PPP1R1B), although its properties are not restricted to PP1 inhibition (see below). DARPP-32 is expressed only in some specific neuronal populations in the brain and at low levels in a few non-neuronal cell types in the brain (e.g., tanycytes, choroid plexus) and other organs (e.g., adrenal medulla, parathyroid cells, kidney thick ascending limb of the loop of Henle; Ouimet et al., 1984; Hemmings and Greengard, 1986; Meister et al., 1989). Not all of these cells express adenylyl-cyclase-coupled DA receptors (D1R and D5R) and DARPP-32 phosphorylation on 
the cAMP site (Thr-34; Hemmings et al., 1984c) can be regulated by many other extracellular messengers (see Greengard et al., 1999; Girault and Greengard, 2004; Svenningsson et al., 2004 for reviews). Thus, DARPP-32 has been implicated in many physiological and pathological responses involving the basal ganglia, and other brain regions and peripheral organs. Here we review the major molecular properties of DARPP-32 and we focus on recent findings on its possible roles based on studies in animal models as well as on correlations in humans. We also try to put its molecular properties in perspective with the known function of striatal neurons.

\section{MOLECULAR PROPERTIES OF DARPP-32}

\section{DARPP-32 IS A PHOSPHORYLATION-DEPENDENT INHIBITOR OF PP1} REGULATED BY CYCLIC NUCLEOTIDES-DEPENDENT PROTEIN KINASES

The biochemical properties of DARPP-32 have raised a great interest because of the surprising complexity of the effects of its phosphorylation at various sites. The most extensively studied is the phosphorylation of Thr-34 which turns DARPP-32 into a potent inhibitor of PP1 (Hemmings et al., 1984a). Thr-34 in DARPP-32, like Thr-35 in inhibitor-1 are excellent substrates for both PKA and cGMP-dependent protein kinases (Hemmings et al., 1984b). They are dephosphorylated by the calcium/calmodulin activated phosphatase 2B (PP2B, also known as calcineurin or PPP3) and by the catalytic subunit of protein phosphatase 2A (PP2A or PPP2) in vitro (Hemmings et al., 1984a; King et al., 1984) and in striatal neurons (Halpain et al., 1990; Nishi et al., 1999).

Protein phosphatase-1 is a major, highly conserved Ser/Thr phosphatase, involved in virtually all cell functions including cell cycle, muscle contraction, carbohydrate metabolism, neuronal signaling, and transcription (see Bollen et al., 2010 for a recent review). The activity of PP1 catalytic subunit (PP1c) is controlled by numerous interacting proteins acting as targeting subunits, substrates, and/or inhibitors (Bollen et al., 2010). Most of these proteins contain a degenerate docking sequence K/R-K/R-V/I-x-F/W necessary for binding PP1c, without changing its conformation (Egloff et al., 1997; Bollen et al., 2010). It has been shown by X-ray crystallography that this motif interacts with a hydrophobic channel located on the opposite side of PP1c active site (Egloff et al., 1997). However, binding to this motif does not inhibit PP1, implying that other domains of inhibitors must interact with the phosphatase to regulate its activity. The docking motif is also found in targeting subunits and can compartmentalize PP1, bringing it into proximity to its substrates, including GADD34, the myosin phosphatase targeting subunit MYPT1, PNUTS, and spinophilin (see Bollen et al., 2010 for references). Among PP1 inhibitors the PPP1R1 family includes inhibitor-1 (PPP1R1A; Aitken et al., 1982), DARPP-32 (PPPR1B), and the much less well characterized inhibitor of protein phosphatase 5 (IPP-5 or PPP1R1C; Wang et al., 2008), which share a conserved region of about 50-residues (Figure 1). Phylogenetic studies using immunoblotting detected DARPP32-like proteins in dopaminoceptive brain regions from representative members of the amniote vertebrate classes (birds and reptiles), while none was identified in dopaminoceptive brain regions from representative members of the anamniote vertebrate classes (bony fishes and amphibians; Hemmings and Greengard, 1986). With the same approach inhibitor-1-like immunoreactivity was detected in anamniote and amphibian representatives (Hemmings et al., 1992). However such studies are limited by the lack of conservation of epitopes. Indeed sequence comparisons show that all three PPP1R1 family members are actually found in Osteichthyes including bony fish, amphibians lizards, birds, and mammals (Figure 2). We also detected short predicted sequences similar to PPP1R1B and PPP1R1C in Elephant shark genome (http://esharkgenome.imcb.a-star.edu.sg/), a cartilaginous fish, although the sequence coverage is not yet sufficient to determine precisely the conservation of these genes in Chondrichthyes. In contrast no homologous sequence was found in Petromyzontoids (jawless fish, e.g., lamprey) and invertebrates. These data, albeit still incomplete, suggest that the PP1R1 family arose in early vertebrate ancestors, possibly in Gnathostomes, which encompass both bony and cartilaginous fish.

pT34-DARPP-32 inhibits PP1c with mixed competitive and uncompetitive kinetics (Hemmings et al., 1984a, 1990). Residues $8-38$, which are highly conserved between the three members of the PPP1R1 family are necessary and sufficient for PP1 inhibition (Hemmings et al., 1990). The N-terminal region of DARPP-32 encompasses a $\mathrm{K}_{7} \mathrm{KIQF}$ motif that corresponds to the canonical PP1 interacting motif. This motif is essential for PP1 inhibition (Kwon et al., 1997) and probably accounts in part for the ability of dephospho-DARPP-32 or Thr-34-Ala DARPP-32 to inhibit

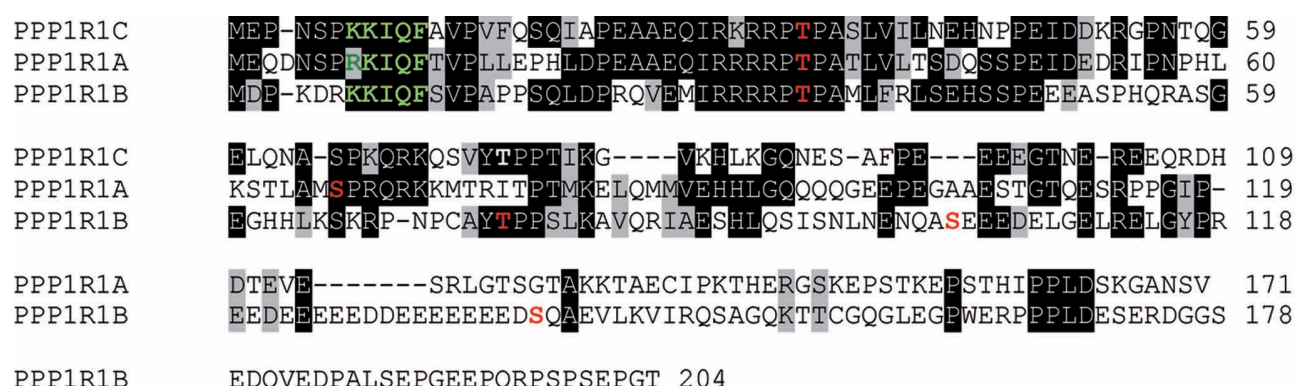

FIGURE 1 | Multiple sequence alignment of human PPP1R1 family members. Human amino acid sequences of PPP1R1C (IPP-5, gi|17389867|gb|AAH17943.1|), PPP1R1A (|-1, gi|48146123|emb|CAG33284.1|), and PPP1R1B (DARPP-32, gi|119580986|gb|EAW60582.1|) were obtained from $\mathrm{NCBI}$ data base and aligned by Clustalview. Identical residues are shaded black and similar ones gray. The known phosphorylation sites are in red and the PP1 binding motif in green. 


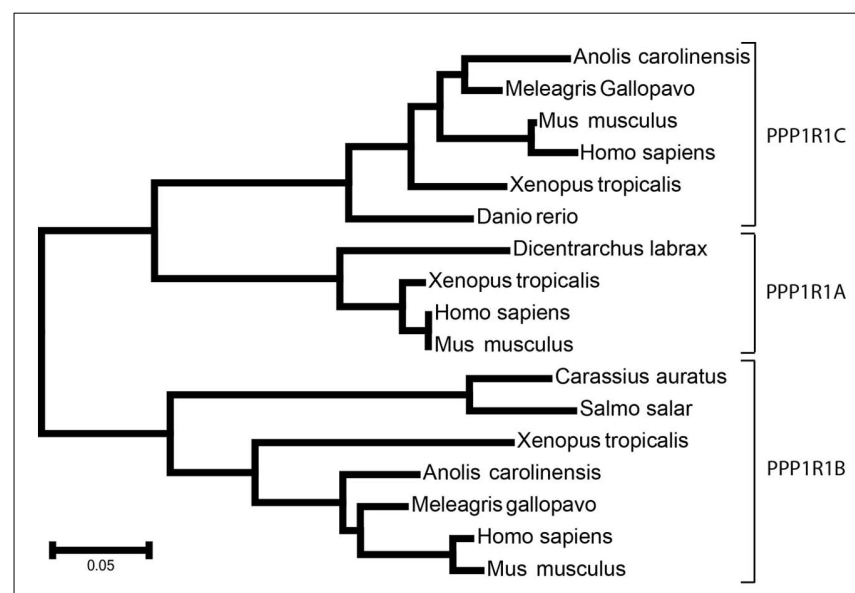

FIGURE 2 | Phylogeny of PPP1R1 family. The evolutionary history was inferred using the Neighbor-Joining method (Saitou and Nei, 1987). The optimal tree with the sum of branch lengths $=1.395$ is shown. The tree is drawn to scale, with branch lengths in the same units as the evolutionary distances used to infer the phylogenetic tree (number of amino acid differences per site). The evolutionary distances were computed using the p-distance method (Nei and Kumar, 2000). Positions containing gaps and missing data were eliminated. There were a total of 42 positions in the final dataset. Evolutionary analyses were conducted in MEGA5 (Tamura et al., 2011). The 17-amino acid sequences analyzed were: PPP1R1A gi|326935910| ref|XP_003214007.1| (Meleagris gallopavo, wild turkey), gi|227337247|gb|ACP21475.1| (Carassius auratus, gold fish), gi|48146123| emb|CAG33284.1| (Homo sapiens), gi|10946734| ref|NP_067366.1| (Mus musculus house mouse), gi|62859473| ref|NP_001015900.1| (Xenopus tropicalis, Western clawed frog); PPP1R1B: gi|119580986| gb|EAW60582.1| (Homo sapiens), gi|21536256| ref|NP_659077.1| (M. musculus), gi|156717604| ref|NP_001096342.1| (X. tropicalis), gi|327275684| ref|XP_003222603.1| (Anolis carolinensis, Carolina anole, a lizard), gi|326936204| ref|XP_003214147.1| (M. gallopavo), gi|213515022| ref|NP_001133145.1| (Salmo salar, Atlantic salmon); PPP1R1C: gi|50540138| ref|NP_001002538.1| (Danio rerio, zebrafish), gi|327278420| ref|XP_003223960.1| (A. carolinensis), gi|122889495| emb|CAM14502.1| (M. musculus), gi|17389867| gb|AAH17943.1| (Homo sapiens), gi|284413766| ref|NP_001165134.1| (X. tropicalis), gi|326922651| ref|XP_003207562.1| (M. gallopavo).

PP1 with an IC50 in the micromolar range (Desdouits et al., 1995a). Phosphorylation of Thr-34 provides a high affinity inhibition (nanomolar IC50), whereas the replacement of pThr by pSer or Glu is much less efficient (Hemmings et al., 1990; Desdouits et al., 1998). The two Pro residues flanking Thr-34 are also important, as well as the distance between the KKIQF and PpTP motifs (Huang et al., 1999). Thus, it is highly likely that inhibition by DARPP-32 results from a bidentate interaction with PP1c, involving regions located on two opposite sides of the phosphatase: binding of the KKIQF motif to the superficial hydrophobic channel and interaction of PpTP with the active site in a conformation that does not allow dephosphorylation (Hemmings et al., 1990; Kwon et al., 1997; Huang et al., 1999). Like several other PP1 inhibitors, DARPP-32 appears to be an intrinsically disordered protein with little identifiable secondary structure (Neyroz et al., 1993; Dancheck et al., 2008; Marsh et al., 2010), a particularity that may be well suited for a flexible interaction with two diametrically opposed binding sites on PP1c.

\section{DARPP-32 IS PHOSPHORYLATED BY SEVERAL KINASES WITH MULTIPLE CONSEQUENCES}

DARPP-32 is regulated by multiple phosphorylation sites (Figure 3). Cdk5, a cyclin-dependent kinase family member activated in neurons by its co-factor p35, phosphorylates DARPP-32 on Thr-75 (Bibb et al., 1999). When it is phosphorylated on Thr-75, DARPP-32 inhibits PKA in vitro with a purely competitive kinetics and a $\mathrm{Ki}$ of $2.7 \mu \mathrm{M}$ using cAMP-regulated phospho-protein of $21 \mathrm{kDa}$ (ARPP-21, also known as regulator of calmodulin signaling, RCS) as a substrate (Bibb et al., 1999). DARPP-32 is also phosphorylated on Ser-45 and Ser-97 (Ser-102 in rat sequence) by casein kinase 2 (CK2; Girault et al., 1989a). Phosphorylation by CK2 increases the action of PKA on Thr-34, but not that of cGMPdependent protein kinase on that site (Girault et al., 1989a). It is not known whether this effect results from phosphorylation of Ser- 45 or Ser-97, or both, nor what the physiological relevance of this facilitation is in vivo. An important effect of phosphorylation of Ser-97 is to enhance the nuclear export of DARPP-32 (Stipanovich et al., 2008 see below). DARPP-32 is also phosphorylated on Ser-130 (Ser-137 in rat) by casein kinase 1 (CK1; Desdouits et al., 1995b), and this phosphorylation decreases the dephosphorylation of Thr-34 by calcineurin, in vitro and in vivo (Desdouits et al., 1995c). The molecular mechanisms underlying the modulatory effects of CK1 and CK2 are not elucidated. Since DARPP-32 appears to be intrinsically unstructured, it is unlikely that the facilitation of PKA action and inhibition of calcineurin action result from allosteric effects stricto sensu. Instead they may be related to changes in interactions with the relevant enzymes through distant binding sites, and/or to intramolecular folding and interactions within the DARPP-32 molecule, as suggested by NMR studies (Dancheck et al., 2008). In addition to the sites described above, Ser-192 has also been found to be phosphorylated in mouse brain (Jin et al., 2005), but this site is not conserved in several mammalian species and its functional role, if any, is not known.

The dephosphorylation of DARPP-32 by various protein phosphatases has been studied in vitro and in intact cells. Calcineurin dephosphorylates Thr-34 (King et al., 1984; Halpain et al., 1990; Nishi et al., 1999), PP2A dephosphorylates Thr-34, Ser-45, Thr-75, and Ser-97 (Girault et al., 1989a; Hemmings et al., 1990; Bibb et al., 1999; Nishi et al., 1999). In striatal neurons dephosphorylation of Ser-130 is mostly accounted for by PP2C (Desdouits et al., 1998). PP2A is an heterotrimeric enzyme comprising a catalytic subunit $\mathrm{C}$, a scaffolding subunit $\mathrm{A}$, and a variable regulatory subunit $\mathrm{B}$ (Janssens et al., 2008). The B56 $\delta$ subunit (also known as PR61 $\delta$, $\mathrm{B}^{\prime} \delta$ or PPP2R5D) is enriched in the striatum and mediates dephosphorylation of Thr-75 and Ser-97 in response to PKA activation (Nishi et al., 2000a; Ahn et al., 2007a; Stipanovich et al., 2008). The PR72/B' (PPP2R3A) subunit, which contains two $\mathrm{Ca}^{2+}$ binding sites, accounts for the $\mathrm{Ca}^{2+}$-induced dephosphorylation of Thr75 (Nishi et al., 2002; Ahn et al., 2007b). Thus, the activity of PP2A appears to be regulated by multiple pathways which depend on the nature of the regulatory and inhibitory subunits that are expressed in the cell. An additional layer of regulation potentially important in striatal neurons has been revealed recently by the discovery that proteins related to ARPP-16, which is enriched in striatal neurons (Girault et al., 1990), are potent inhibitors of PP2A (GharbiAyachi et al., 2010; Mochida et al., 2010). This effect requires 


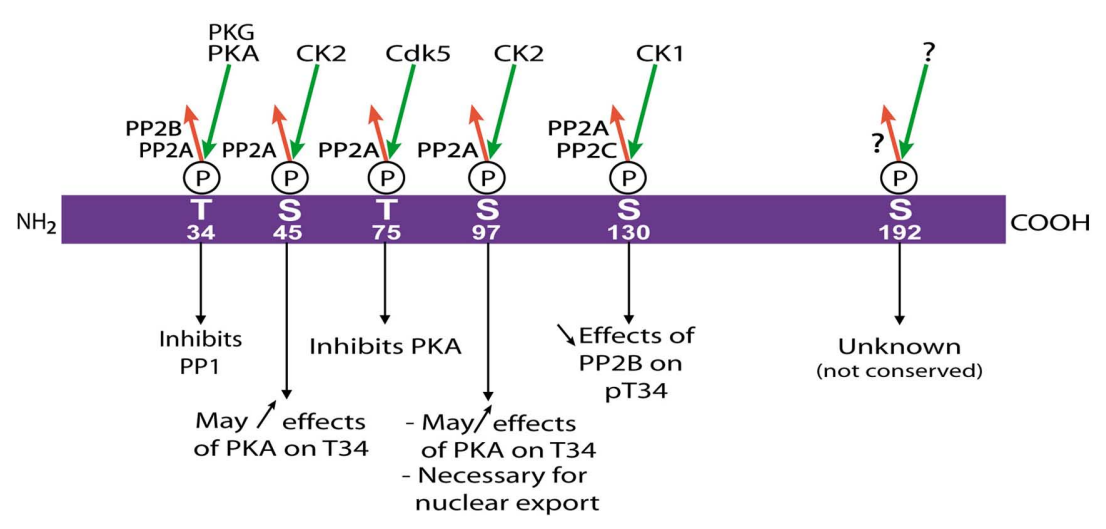

FIGURE 3 | Multisite phosphorylation of DARPP-32. Schematic representation of mouse DARPP-32 with the residues that have been found phosphorylated in vivo (Thr-34, Ser-45, Thr-75, Ser-97, Ser-130, Ser-192). The identified kinases are indicated above green arrows (phosphorylation), and protein phosphatases beside the red arrows (dephosphorylation). The role of the phosphorylation is given for each residue. See the text for discussion and references. $\mathrm{P}$, phosphate.

phosphorylation by Greatwall, a PKA that has several orthologous isoforms in mammals (microtubule associated serine/threonine kinase like, MASTL1-4). The role of this pathway on PP2A regulation and indirectly on PP1 in the striatum remains to be investigated. Another interesting regulation of PP2A in D2R-expressing neurons is related to its recruitment by $\beta$-arrestin following receptor internalization (Beaulieu et al., 2005), but its role in the regulation of DARPP-32 has not been investigated.

The phosphorylation sites of DARPP-32 and their effects on kinases and phosphatases, including those which act on DARPP-32 itself, weave a complex network of positive and negative feedback and feedforward loops. Several computational models have been built to better understand the complex regulation of these four sites and predict the output of the pathway depending on the levels of DA and glutamate, or of cAMP and $\mathrm{Ca}^{2+}$ (Fernandez et al., 2006; Lindskog et al., 2006; Barbano et al., 2007; Le Novère et al., 2008; Nakano et al., 2010; Qi et al., 2010). Kinetic models using differential equations showed that DARPP-32 is not only a robust signal integrator, but that its response also depends on the delay between CAMP and calcium signals (Fernandez et al., 2006) and that Thr-34 phosphorylation is potentiated by the coincidence of the two stimuli (Lindskog et al., 2006). DARPP-32 appears capable to translate the various states of glutamate and DA input into distinct steady states and/or dynamic responses (Qi et al., 2010) and the positive feedback loop consisting of PKA, PP2A, and Thr-75 phosphorylation may serve as a major switch for inducing LTD and LTP (Nakano et al., 2010). Interestingly this loop displayed robust bi-stable responses but was disrupted by high basal levels of DA. Other authors have used large-scale numerical simulation and sophisticated mathematical approach to model the DARPP32 network and evaluate its resistance to perturbations (Barbano et al., 2007) ${ }^{1}$. They showed that the global network topology stabilized the net state of DARPP-32 phosphorylation in response to

\footnotetext{
${ }^{1}$ The approach of Barbano et al. (2007) does not require knowledge of initial concentrations or kinetic parameters, but uses random arbitrary values to calculate steady state equilibrium concentrations of all chemical reagents for various ratios of DA and glutamate inputs. Simulations are repeated in the presence of superimposed noise. The results of each simulation represent coordinates of a single point
}

variations of the input levels of DA and glutamate, despite significant perturbation to the concentrations and levels of activity of a number of intermediate chemical species (Barbano et al., 2007). Interestingly the whole network used in the model was necessary to provide this resistance to perturbation, providing a possible $a$ posteriori justification for its apparent complexity. Altogether these modeling studies indicate that DARPP-32 is a very robust sensor of glutamate and DA inputs with intrinsic abilities to stably orient the cell responses in the presence of noise. This may suggest that a major function of DARPP-32 is to increase the reliability of signal processing in medium-size spiny neurons (MSNs) of the striatum.

\section{DARPP-32 IS A MESSENGER BETWEEN THE CYTOPLASM AND THE NUCLEUS}

Since PP1 dephosphorylates many targets of PKA in neurons, DARPP-32 has been implicated in the regulation by DA of several ion channels in striatal neurons, including the AMPA and NMDA glutamate receptors (NMDAR) and voltage-gated $\mathrm{Na}^{+}$and $\mathrm{Ca}^{2+}$ channels (see Svenningsson et al., 2004 for a review). A recent study has revealed an additional level of complexity concerning the signaling properties of DARPP-32, by showing its regulated cytonuclear trafficking (Stipanovich et al., 2008). Although the presence of DARPP-32 immunoreactivity in the nucleus of some striatal MSNs, but not in others, was clearly established by electron microscopy early in the study of this protein (Ouimet and Greengard, 1990), the significance of this observation was unclear. Studies in neurons in culture with the inhibitor of nuclear export leptomycin B revealed that DARPP-32 undergoes a continuous shuttling between the cytoplasm and the nucleus (Stipanovich et al., 2008). Its import is facilitated by several sequences in the $\mathrm{N}$-terminal region, while the nuclear export requires a specific sequence with nuclear export signal features and the phosphorylation of Ser-97. Accordingly, the protein is mostly found in

in a space with as many dimensions as reagents in the network. The authors then use non-linear dimensionality reduction methods, such as locally linear embedding, to compare the resulting curves in the absence or presence of various amounts of noise and determine the resistance of the network to perturbations. 
the nucleus in knock-in mice bearing a Ser-97-Ala DARPP-32 mutation (Stipanovich et al., 2008). Treatment of mice with addictive drugs or operant learning increases the proportion of nuclear DARPP-32, a response mimicked in vitro by cAMP analogs (Stipanovich et al., 2008). Dephosphorylation of Ser-97 by PP2A is an important factor in these regulations. It can be triggered by activation of the isoform containing the B56 $\delta$ subunit (Stipanovich et al., 2008), as well as by other signaling pathways (Matamales and Girault, unpublished observations).

PP1 is present in the nucleus of cells where it plays important roles (Moorhead et al., 2007) with PP1 $\alpha$ being the predominant nuclear isoform in MSNs (Ouimet et al., 1995). Following activation of D1R, pT34-DARPP-32 is enriched in the nucleus and this facilitates the phosphorylation of histone $\mathrm{H} 3$ on Ser10 (Stipanovich et al., 2008), a site dephosphorylated by PP1 (Hsu et al., 2000). Phosphorylation of histone H3 Ser-10 during the interphase promotes detachment of specific regions from the heterochromatic scaffold to allow decondensation and gene expression, in combination with other histone post-translational modifications (Johansen and Johansen, 2006). Since PP1 has many substrates in the nucleus (Moorhead et al., 2007), it is likely that the consequences of the accumulation of pT34-DARPP-32 has multiple consequences on chromatin and other nuclear targets. For example, a recent report shows that DARPP-32 interacts with tra2-beta1, a factor involved in the regulation of alternative splicing (Benderska et al., 2010). This latter observation suggests a possible role of DARPP-32 in the regulation of alternative splicing an important but little understood process in neurons.

\section{DISTINCT ROLES OF DARPP-32 IN STRIATO-NIGRAL AND STRIATO-PALLIDAL MSNs DARPP-32 IS HIGHLY CONCENTRATED IN ALL STRIATAL MEDIUM-SIZE SPINY NEURONS}

DARPP-32 concentrations are the highest $(20-50 \mu \mathrm{M})$ in striatal MSNs (Hemmings and Greengard, 1986). The striatum, which consists of a dorsal region, the caudate-putamen (CP), and a ventral region, the nucleus accumbens (NAc), is the major entry station of the basal ganglia. It is comprised of MSNs which are GABAergic efferent neurons making up to $95 \%$ of striatal neurons in rodents, and of several types of interneurons, including large cholinergic and diverse medium-size GABAergic neurons (Tepper and Bolam, 2004). MSNs receive massive glutamatergic inputs from virtually all cortical areas and the thalamus, and a dense dopaminergic innervation from the substantia nigra pars compacta (dorsolateral CP) and the ventral tegmental area (VTA; dorsomedial CP and NAc). MSNs belong to two different populations which project to the substantia nigra pars reticulata either directly or indirectly through relays in the lateral globus pallidus and subthalamic nucleus. D1 DA receptors (D1R) are preferentially expressed in striato-nigral MSNs of the direct pathway and D2R in striato-pallidal MSNs of the indirect pathway (Gerfen et al., 1990; see also Valjent et al., 2009; Bertran-Gonzalez et al., 2010 for recent reviews). Thus, the circuits in which MSNs play an essential role integrate signals coming from many brain regions with modulatory information coded by DA neurons in relation with reward prediction errors (Schultz, 2002) and motivational salience (Bromberg-Martin et al., 2010). The basal ganglia loops control many aspects of movements and motivation and their function has been proposed to be related to action selection (Mink, 1996; Redgrave et al., 1999). This is dependent on the balance between the two trans-striatal circuits, involving the direct and indirect pathways. Their disequilibrium accounts for the consequences of the striatal alterations in several pathological conditions, including Parkinson's disease due to the lack of DA following degeneration of DA neurons and addiction, related to the common capacity of abused substances to increase extracellular DA (Di Chiara, 1999). DARPP-32 has been implicated in various aspects of striatal functions and dysfunctions, with distinct consequences in the direct and indirect pathways.

\section{DARPP-32 IS DIFFERENTIALLY REGULATED IN THE TWO POPULATIONS OF MSNs}

DARPP-32 is present in virtually all MSNs (Ouimet et al., 1998) and equally expressed in the D1R-expressing striato-nigral neurons (indirect pathway) and D2R-expressing striato-pallidal neurons (direct pathway; Bertran-Gonzalez et al., 2008). A number of drugs have been reported to alter DARPP-32 phosphorylation at its various sites in striatal slices in vitro and in the striatum in vivo (see Svenningsson et al., 2004). Some of these studies apparently had contradictory results, showing for example that agents that either increase DA transmission, such as cocaine, or block DA transmission, such as antipsychotics, both increased DARPP-32 phosphorylation on Thr-34 (Svenningsson et al., 2000). The fact that increased phosphorylation was due to stimulation of D1R or blockade of D2R, and that the latter effect was prevented by A2a antagonists ${ }^{2}$ suggested that this effect was due to the different regulation of DARPP-32 in D1R- and D2R-expressing MSNs (Svenningsson et al., 2000). This hypothesis was formally proven by the use of bacterial artificial chromosome (BAC) transgenic mice expressing DARPP-32 fused to two different peptide tags, under the control of $d r d 1 a(\mathrm{D} 1 \mathrm{R})$ or $d r d 2$ (D2R) promoters, respectively (Bateup et al., 2008). Selective immunoprecipitation with antibodies against one peptide tag or the other showed that, as expected, cocaine-induced phosphorylation of DARPP-32 at Thr-34 in D1Rneurons and decreased it in D2R- neurons, while it decreased Thr-75 phosphorylation in D1R- and increased it in D2R-neurons (Bateup et al., 2008). Haloperidol increased selectively Thr-34 phosphorylation in D2R-neurons. Surprisingly however, the in vivo effects of selective D1R or D2R agonists appeared more complex: SKF81297, a D1R agonist, increased Thr-34 phosphorylation in both neuronal populations, whereas quinpirole, a D2R agonist, decreased Thr-34 and increased Thr-75 phosphorylation in both neuronal populations (Bateup et al., 2008). The effects of the D2 agonist on D1R-expressing neurons were easily explained by the decreased release of endogenous DA following the stimulation of D2 autoreceptors on DA terminals. In contrast, the mechanisms of the effects of the D1 agonist on D2Rexpressing neurons were not completely clear and may reflect the recruitment of extrastriatal D1R. It is interesting to note that in the study of Bateup et al. (2008), as in others (Bertran-Gonzalez

\footnotetext{
${ }^{2} \mathrm{~A} 2 \mathrm{a}$ receptors are selectively expressed in striato-pallidal neurons in which they stimulate adenylyl-cyclase, thereby opposing the effects of D2R which inhibit adenylyl-cyclase.
} 
et al., 2008), the in vivo actions of cocaine that non-selectively increases extracellular DA and other monoamines, appeared more specific on striato-nigral D1R-expressing neurons than those of selective D1 agonists. This unexpected observation suggests that the coordinated stimulation of D1R and D2R by endogenous DA is particularly well suited to exert contrasted and opposing effects on the two populations of MSNs, probably reflecting a fundamental intrinsic property of the functional organization of the basal ganglia.

\section{THE FUNCTIONAL CONSEQUENCES OF THE ABSENCE OF DARPP-32 ARE DISTINCT IN THE TWO POPULATIONS OF MSNs}

To investigate the role of DARPP-32 in the two populations of striatal MSNs from a behavioral standpoint, Bateup et al. (2010) have used conditional knockout in D1R or in D2R-expressing MSNs. The absence of DARPP-32 in D1R MSNs reduced basal and cocaine-induced locomotor activity whereas the loss of DARPP32 in D2R MSNs had the opposite effect. The opposite effects on motor behavior in the two populations of striatal neurons may explain why the complete knockout had relatively little effect on spontaneous motricity (Fienberg et al., 1998; Hiroi et al., 1999).

In a rodent model of Parkinson's disease, in which the striatal dopaminergic input is destroyed by 6-OH-DA, chronic administration of L-DOPA-induced phosphorylation of DARPP-32 at Thr-34 (Santini et al., 2007). Chronic L-DOPA treatment of DAlesioned rodents often triggers abnormal involuntary movements (AIMs), which are thought to model L-DOPA-induced dyskinesia observed in patients (Cenci, 2007). Interestingly, phosphorylation of both DARPP-32 and extracellular signal regulated kinase (ERK) was correlated with the occurrence of AIMs (Santini et al., 2007). D1R is critical for the development of L-DOPA-induced AIMS (Darmopil et al., 2009) and L-DOPA selectively induced ERK phosphorylation in D1R-expressing neurons (Santini et al., 2009). AIMs induction was diminished when L-DOPA was administered with a drug preventing ERK activation or in DARPP-32 knockout mice (Santini et al., 2007). Although this suggests a causal relationship between DARPP-32 phosphorylation and ERK activation (Santini et al., 2007), other authors found that ERK phosphorylation was not blocked in the dorsal striatum in similar conditions (Gerfen et al., 2008). The reason for this discrepancy is not known. However, the prominent role of DARPP-32 in striatonigral neurons in the generation of L-DOPA-induced AIMs was shown by their absence in mice in which DARPP-32 was deleted in D1R-expressing neurons, but not in those in which the deletion was induced in D2R-expressing neurons (Bateup et al., 2010). This result is in agreement with those obtained in D1R knockout mice (Darmopil et al., 2009). In conclusion, the ERK pathway and DARPP-32 in striato-nigral neurons appear to be both involved in the appearance of AIMs but the precise relationship between the two is not fully understood.

\section{MULTIPLE ROLES OF DARPP-32 IN REWARD AND THE ACTION OF DRUGS OF ABUSE}

It is well established that the mesencephalic DA neurons play an important role in reward-related behaviors (see for example Schultz, 2002 for a review). Little is known about the involvement of DARPP-32 in physiological reward-controlled learning.
Although DARPP-32 seems not to be crucial for reward learning, the reversal learning after a conditioning operant task by nose poking was impaired in DARPP-32 KO mice (Heyser et al., 2000). In knock-in mice with a Ser-97-Ala point mutation, operant learning was normal but the motivation for food reward was decreased (Stipanovich et al., 2008). Drugs of abuse share the ability to increase DA transmission (Wise, 1987; Di Chiara, 1999), and the role of DARPP-32 in mediating their actions has been studied for molecules as different as cocaine, amphetamine, nicotine, caffeine, ethanol, and opiates (see Nairn et al., 2004 for a review). One of the signaling pathways which appear to be important for the long-term behavioral effects of drugs of abuse is the ERK cascade which is activated in response to all tested drugs of abuse (Valjent et al., 2000, 2004; Ibba et al., 2009). ERK phosphorylation requires activation of both D1R and NMDAR, occurs in D1R-expressing neurons, and is prevented in DARPP-32 knockout or Thr-34-Ala knock-in mice (Valjent et al., 2005). Thus, although DARPP-32 is not necessary for the potentiation of NMDAR by D1R that leads to ERK phosphorylation in neurons in culture (Pascoli et al., 2011), it appears to be necessary for the activation of ERK by various drugs of abuse in vivo (Valjent et al., 2005). DARPP-32 regulates dephosphorylation of ERK by controlling the state of phosphorylation and activity of the non-receptor striatal-enriched phosphatase (STEP) and also acts upstream in the pathway (Valjent et al., 2005). Here we summarize results implicating DARPP-32 in the actions of drugs of abuse and focus on recent work, including studies in which the role of individual phosphorylation sites of DARPP-32 has been studied (Svenningsson et al., 2003).

\section{COCAINE AND AMPHETAMINE}

Cocaine inhibits reuptake of dopamine and amphetamine triggers the release of dopamine from nerves terminals. Acute exposure to cocaine or amphetamine increased the phosphorylation of DARPP-32 at Thr-34 and decreased the phosphorylation at Thr-75 in striatal slices (Nishi et al., 2000b). In vivo, an acute injection of cocaine $(20 \mathrm{mg} / \mathrm{kg})$ increased Thr-34 phosphorylation in D1R-expressing neurons (Bateup et al., 2008). This treatment had opposite effects on Thr-75 phosphorylation in D1R striato-nigral neurons (decreased phosphorylation) and in D2R striato-pallidal neurons (increased phosphorylation), with an overall decreased phosphorylation (Bateup et al., 2008). In contrast, chronic exposure to cocaine-induced an increase of phosphorylation at Thr-75 (Bibb et al., 2001). This effect was attributed to the up-regulation of Cdk5, resulting from an over-expression of $\Delta$-Fos $B$ after a chronic exposure (Bibb et al., 2001).

Repeated administration of psychostimulants in rodents is accompanied by an increased locomotor response, termed locomotor or psychomotor sensitization (Vezina and Leyton, 2009). Locomotor sensitization was increased when cocaine was repeatedly administered in the presence of a Cdk5 inhibitor (Bibb et al., 2001), supporting a negative role of the phosphorylation of Thr75 and/or other targets. However, contrary to what might have been predicted, Thr-34-Ala point mutation increased locomotor sensitization to repeated administration of cocaine in knock-in mutant mice, whereas Thr-75-Ala mutation point prevented sensitization (Zachariou et al., 2006). An increased sensitization was also observed in complete knockout mice in response to repeated 
cocaine (Hiroi et al., 1999). A strong and long-lasting sensitization can be induced in rats or mice in response to a single injection of cocaine or amphetamine, attesting to the powerful effects of these drugs on neuronal plasticity (Vanderschuren et al., 1999; Valjent et al., 2010). Using this protocol, sensitization to a single injection of cocaine was markedly decreased in Thr-34-Ala mutant mice (Valjent et al., 2005). These discrepancies may be related to different mechanisms underlying sensitization in response to single and repeated drug injections and/or to minor differences in the experimental protocols which are highly sensitive to conditioned cues (Vezina and Leyton, 2009).

Conditioned place preference (CPP) to cocaine was diminished in full knockout (Hiroi et al., 1999) and in Thr-34-Ala knockin DARPP-32 mutant mice (Zachariou et al., 2002). Locomotor sensitization and CPP were also decreased in DARPP-32 Ser-97Ala mutant mice, in which DARPP-32 is mostly trapped in the nucleus (Stipanovich et al., 2008). Acquisition of stable cocaine self-administration required significantly more time in Thr-34Ala mice, although both Thr-34-Ala and Ser-130-Ala DARPP-32 mutant mice self-administered more cocaine than their respective wild-type controls (Zhang et al., 2006). Thus it appears that DARPP-32 is involved in the chronic effects of psychostimulants, although its role is not simple. Its loss of function delays or impairs the acquisition of cocaine conditioned behavior, but may limit locomotor sensitization to repeated administration and self-administration.

\section{MORPHINE}

Morphine and heroin are thought to exert their addictive effects at several levels. They increase the firing of DA neurons by decreasing at the presynaptic level the inhibitory input to these neurons and also act directly in the NAc (see Luscher and Malenka, 2011 for a review). Acute locomotor effects of morphine were decreased in Thr-34-Ala mutant mice, whereas locomotor sensitization to repeated injections and CPP were unaltered (Borgkvist et al., 2007). In contrast, sensitization to a single injection of morphine was markedly decreased in Thr-34-Ala mutant mice (Valjent et al., 2010), and in Ser-97-Ala mutant mice (Stipanovich et al., 2008). Thus, modulation of the behavioral effects of psychostimulants and morphine by DARPP-32 appear to be different depending on whether the drug is administered once or repeatedly. Following a single administration DARPP-32 seems to amplify the effects of the drugs and to be necessary for long-term plasticity. In contrast, following repeated administration, it appears to moderate the effects in a somewhat homeostatic fashion.

\section{CAFFEINE}

Caffeine is a commonly used minor psychostimulant, which exerts its effects mostly through antagonism of A2 adenosine receptors $\left(\mathrm{A}_{2 \mathrm{~A}} \mathrm{R}\right)$, located in the striato-pallidal neurons of the indirect pathway (Ledent et al., 1997). It is not considered as a drug of abuse and has little or no addictive properties (Satel, 2006). $\mathrm{A}_{2 \mathrm{~A}} \mathrm{R}$ are coupled to $\mathrm{G}_{\text {olf }}$ and stimulate cAMP production (Kull et al., 2000; Corvol et al., 2001). DARPP-32 is necessary to mediate the psychostimulant effects of caffeine (Lindskog et al., 2002). This may be related to the increase in Thr-75 phosphorylation, which results from an inhibition of PP2A (Lindskog et al., 2002) and occurs selectively in striato-pallidal neurons (Bateup et al., 2010). These results further support the precise functional balance between the striato-nigral and striato-pallidal neurons and suggest that decreased signaling in one pathway (here PKA inhibition through phospho-Thr-75-DARPP-32) has effects similar to stimulation of signaling in the other pathway (e.g., stimulation of PKA/phospho-Thr-34-DARPP-32 by D1R).

\section{NICOTINE}

Nicotine enhances dopamine release by the nigrostriatal and preferentially mesolimbic dopaminergic systems, in vitro and in vivo (Giorguieff Chesselet et al., 1979; Imperato et al., 1986). In striatal slices nicotine at low concentration $(1 \mu \mathrm{M})$ decreased phosphorylation of DARPP-32 at Thr-34, whereas at high concentration $(100 \mu \mathrm{M})$ it increased phosphorylation of Thr-34, as well as Ser102, Ser-137, and, with a delay, decreased Thr- 75 phosphorylation (Hamada et al., 2004, 2005). In vivo, however, nicotine increased phosphorylation of both Thr-34 and Thr-75 (Zhu et al., 2005). Interestingly DARPP-32 knockout mice had an increased responsiveness to nicotine including a higher oral intake of the drug, suggesting that the "inhibitory" effect of Thr-75 plays a predominant role (Zhu et al., 2005).

\section{THE ROLE OF SEROTONIN AND NOREPINEPHRINE}

Psychostimulants increase not only extracellular dopamine but also serotonin (5OH-tryptamine, 5HT) and norepinephrine. In the striatum, stimulation of 5HT-4 and 5HT-6 receptors increases phosphorylation of DARPP-32 on Thr-34 and decreases its phosphorylation on Thr-75, while stimulation of 5HT-2 receptors enhances Ser-130 (Ser-137 in the rat) phosphorylation (Svenningsson et al., 2002a). Similar effects were observed after acute or chronic administration of the selective serotonin reuptake inhibitor fluoxetine (Svenningsson et al., 2002b). The regulation of DARPP-32 by 5 HT may be functionally relevant since the behavioral effects of various agents that raise 5HT levels in vivo including 5-OH-tryptophan, $p$-chloroamphetamine, and fluoxetine were decreased in DARPP-32 knockout mice (Svenningsson et al., 2002a,b). The phosphorylation of DARPP-32 on the sites mentioned above was also regulated following administration of psychotomimetic compounds acting through diverse mechanisms, including amphetamine, lysergic acid diethylamide (LSD, predominantly a 5HT2A agonist), and phencyclidine (an NMDA antagonist; Svenningsson et al., 2003). The behavioral effects of these drugs were altered in knock-in mice with point mutations of either Thr-34 or Ser-130 (Svenningsson et al., 2003). Interestingly, DARPP-32 Thr-34 phosphorylation is also regulated by adrenoceptors in striatal slices with a stimulatory effect of $\beta 1$-adrenoceptors in both striato-nigral and striato-pallidal neurons (Hara et al., 2010). These results support the implication of DARPP-32 far beyond the DA receptors that may contribute to the role of this protein in the action of drugs of abuse.

\section{ROLE OF DARPP-32 IN OTHER BRAIN REGIONS}

The initial study of DARPP-32 immunoreactivity in the brain of adult rats showed its abundance in brain regions that receive a strong dopamine input (striatum, olfactory tubercle, bed nucleus 
of the stria terminalis, massa intercalata, and amygdaloid nuclei; Ouimet et al., 1984). Weakly labeled neuronal cell bodies and dendrites were found in the Purkinje neurons of the cerebellum, as well as in certain glial cells, especially in the median eminence, in the arcuate nucleus, and medial habenula (Ouimet et al., 1984). In the rat cerebral cortex DARPP-32 is expressed throughout the neocortex, primarily in layer VI corticothalamic neurons (Ouimet et al., 1984; Ouimet, 1991). DARPP-32 is also found in the monkey cortex with a widespread distribution in the fetus, which becomes more restricted in the adult (Berger et al., 1990). DA signaling in the prefrontal cortex (PFC), which receives dense DA projections from the VTA, has been established to play a critical role in animals' performance in both working memory and selective attention tasks (Goldman-Rakic et al., 2000). D1R and D2R are expressed in the rat PFC, in layers VI and V respectively (Gaspar et al., 1995). The positive effects of a D1R agonist on a recognition and temporal order memory task were associated with increased phosphorylation of DARPP-32 on Thr-34 in the PFC but not in the hippocampus, whereas a D1R antagonist decreased the performance and Thr-34 phosphorylation (Hotte et al., 2006). Moreover, in mice the levels of expression in the PFC of several DA signaling related genes, including DARPP-32, were positively correlated with animals' general cognitive performance (Kolata et al., 2010).

DARPP-32 also appears to play a role in progesteronedependent sexual behavior. Vaginal-cervical stimulation was reported to increase the number of cells exhibiting pThr-34DARPP-32 immunoreactivity in the medial preoptic nucleus, the caudal ventromedial hypothalamic nucleus, the posterodorsal medial amygdala, and the bed nucleus of the stria terminalis, although the total amount of protein was not verified (Meredith et al., 1998). Progesterone enhanced DARPP-32 Thr-34 phosphorylation in the hypothalamus of female rats, independently from D1R (Mani et al., 2000). The role of DARPP-32 in the behavioral effects of progesterone was indicated by the decreased lordosis after injection of DARPP-32 antisense nucleotides in the third ventricle or in DARPP-32 knockout mice (Mani et al., 2000). In addition to its role in brain, DARPP-32 may be involved in sexual hormone action at the peripheral level since it is expressed in ovarian endocrine cells (Mayerhofer et al., 1999). Although reproductive performance is not altered in adult DARPP-32 knockout mice, progressive alterations and derangements of growth and development of ovarian follicles are observed, suggesting premature ovarian aging (Mayerhofer et al., 2004). A recent study has shown that DARPP-32 as well as other DA-related gene products, were upregulated in lateral hypothalamic orexinergic neurons by sodium deficiency (Liedtke et al., 2011). These observations suggest an evolutionary connection between the hypothalamic mechanisms of salt appetite and hedonic liking of salt taste, and possibly also mating behavior, with other D1R-regulated reward systems.

\section{DARPP-32 IN HUMAN PHYSIOLOGY AND PATHOLOGY DARPP-32 IN HUMAN NEUROPSYCHIATRIC DISEASES AND PSYCHOLOGICAL TRAITS}

DARPP-32 mRNA is expressed in the human brain with a distribution similar to that found in monkey and rodents, with high levels in the caudate, putamen, NAc, choroid plexus, and low levels in the cerebral cortex, CA1 and CA3 regions of the hippocampus, amygdala, and Purkinje cells (Brené et al., 1994). In the PFC DARPP-32 mRNA levels increase with age (Colantuoni et al., 2008). Studies of DARPP-32 alterations in humans include measurements in post-mortem tissues using biochemical and immunohistochemical methods, as well as genetic analyses. Expression of DARPP-32 is not changed by the massive alteration in DA innervation in patients with Parkinson's disease or progressive supranuclear palsy (Girault et al., 1989b; Raisman-Vozari et al., 1990). One of the difficulties of studies of human brain samples is the variability of the levels of DARPP-32, as those of several other proteins, with the post-mortem delay, requiring careful matching of delays and large sample size (Girault et al., 1989b). Studies in rodents confirmed the independence of DARPP-32 expression levels from striatal DA innervation during development and following lesions of nigrostriatal neurons (Ehrlich et al., 1990; Raisman-Vozari et al., 1990; Brown et al., 2005). In contrast, a decreased DARPP-32 immunoblot signal was reported in the dorsolateral PFC of schizophrenic patients in comparison to matched controls (Albert et al., 2002). A decreased number of DARPP-32-positive neurons was also observed by immunohistochemistry in the superior temporal gyrus of schizophrenic patients compared to age and sex-matched control subjects (Kunii et al., 2011). Another study reported a decreased level in the dorsal PFC of schizophrenic and bipolar patients (Ishikawa et al., 2007). In contrast to these convergent results on protein levels, results concerning DARPP-32 mRNA levels were variable depending on the studies: unchanged in the dorsal prefrontal and anterior cingulate cortex of elderly schizophrenic patients (Baracskay et al., 2006), or slightly increased in the PFC of schizophrenic and bipolar patients (Zhan et al., 2010), or slightly decreased in schizophrenic patients who died by suicide (Feldcamp et al., 2008). A decreased number of leukocytes expressing DARPP-32 was also reported in schizophrenic and bipolar patients (Torres et al., 2009). Post-mortem studies in humans have intrinsic limitations and the significance of these intriguing findings is unclear. The existence of DARPP-32 alterations in both schizophrenia and bipolar disorder may not be surprising since the limits between these two entities appear less strict than initially thought, as recent studies identify common susceptibility genes (Bondy, 2011). However, both conditions are unlikely to be homogenous, and it is possible that decreased DARPP-32 levels in the cortex are meaningful only in subgroups of patients yet to be identified. Whether these changes are a cause or a consequence of the disease process also remains to be determined. It is unlikely that the changes result from chronic antipsychotic treatment since such treatment did not alter DARPP-32 levels in rodents (Grebb et al., 1990; Souza et al., 2008). In contrast, chronic treatment of rats with lithium or other antidepressants increased DARPP-32 levels in the frontal cortex (Guitart and Nestler, 1992).

$P P P 1 R 1 B$, the gene encoding DARPP-32, is located at $17 \mathrm{q} 21$, in or near a region possibly implicated in risk for schizophrenia by a meta-analysis of whole genome linkage (Lewis et al., 2003). A polymorphism in the $P P P 1 R 1 B$ gene has been identified without association with schizophrenia in Chinese Han (Li et al., 2006; Hu et al., 2007) and Japanese (Yoshimi et al., 2008) populations. Another study in the USA identified a frequent $P P P 1 R 1 B$ 
haplotype predicting mRNA expression of DARPP-32 isoforms in post-mortem human brain (Meyer-Lindenberg et al., 2007). This haplotype was associated with enhanced performance in several cognitive tests that depend on frontostriatal function and increased frontostriatal connectivity in multimodal brain imaging. It was also associated with the risk for schizophrenia in a family based association analysis (Meyer-Lindenberg et al., 2007). Possible links between $P P P 1 R 1 B$ polymorphisms and personality traits have also been studied. A single nucleotide polymorphism $(\mathrm{C} \rightarrow \mathrm{T}$ in intron 5$)$ was associated to self-reports of anger in a German Caucasian population (Reuter et al., 2009). Another study conducted in healthy Chinese Han subjects found a correlation between several SNPs in PPP1RB and traits of personality such as harm avoidance or novelty seeking (Li et al., 2011). A particular haplotype (present in $32 \%$ of the subjects) in PPP1RB was linked to smoking quantity in a European-American cohort but not in an Afro-American one (Beuten et al., 2007). All these association studies are intriguing but at best correlative. Their validity will have to be confirmed by the replication of the associations in similar and different genetic backgrounds.

\section{DARPP-32 SHORT ISOFORM AND CANCER}

Both DARPP-32 and a shorter isoform lacking the $36 \mathrm{~N}$-terminal residues and termed truncated DARPP-32 (t-DARPP) are overexpressed in gastric cancer (El-Rifai et al., 2002). The translation of t-DARPP-32 is initiated at an internal site, Met-37, from an mRNA encompassing an alternative first exon located within intron 1 of DARPP-32 (El-Rifai et al., 2002; Figure 4). This transcript has also been detected in human brain (El-Rifai et al., 2002; MeyerLindenberg et al., 2007). t-DARPP-32 lacks the N-terminal region involved in PP1 inhibition. The physiological role of t-DARPP-32, if any, is not known and Met-37 is not conserved in all species (e.g., it is absent in rat). In contrast t-DARPP may play an important role in human cancer cells. In gastric adenocarcinoma, t-DARPP promotes cell survival through an increase in Bcl2 levels mediated by a pathway involving activation of Akt, CREB, and ATF1 (Belkhiri et al., 2008). t-DARPP is over-expressed in breast cancer cells resistant to herceptin ${ }^{\mathrm{TM}}$, a therapeutic monoclonal antibody that blocks erbB2 (Gu et al., 2009; Hamel et al., 2009). This effect involves phosphorylation of Thr-75 and activation of Akt, and is antagonized by full length DARPP-32 (Gu et al., 2009; Hamel et al., 2009). Interestingly, the effects of t-DARPP-32 are mediated in part by activation of $\beta$-catenin-dependent transcription (Vangamudi et al., 2011). In both breast and upper gastrointestinal tract cancer cells, t-DARPP-32 appears to activate Akt upstream from phosphatidylinositol-3-kinase (Vangamudi et al., 2010, 2011). Another link between DARPP-32 and transformed phenotype has been identified in breast cancer. DARPP-32 binds to the juxtamembrane region of unstimulated discoidin domain receptor-1 (DDR1), a receptor tyrosine kinase activated by collagen (Hansen et al., 2006). Co-expression of the two proteins inhibited cell migration and filopodia formation through phosphorylation of DARPP-32 Thr-34 in response to Wnt-5a activation of cAMP production and PKA (Hansen et al., 2006, 2009). These results are interesting since they identify t-DARPP as a potential therapeutic target in cancer. They also suggest the existence of novel signaling function of this protein that remain to be elucidated at the molecular level but which might also be relevant in neurons.

\section{CONCLUSION}

DARPP-32 is one of several PKA-regulated inhibitors of PP1 and has additional functions which endow it with a large number of possible regulatory roles. DARPP-32 is highly expressed in specific cells especially in neurons, among which the striatal MSNs have the highest DARPP-32 concentration. Its phosphorylation has been thoroughly investigated and DARPP-32 is the hub of a rich network of regulations. It controls an amazingly wide variety of properties of MSNs from ion channel permeability and synaptic plasticity, to nuclear chromatin response. The combination of experimental and modeling studies suggests that in MSNs DARPP-32 is a robust integrator of signaling whose main role may be to increase the reliability in decoding the information mediated by glutamate and DA, as well as other inputs. As such it may not be essential for the basal functioning of the basal ganglia and cortex, but it may perhaps be expected to increase evolutionary fitness by improving performance in challenging conditions.

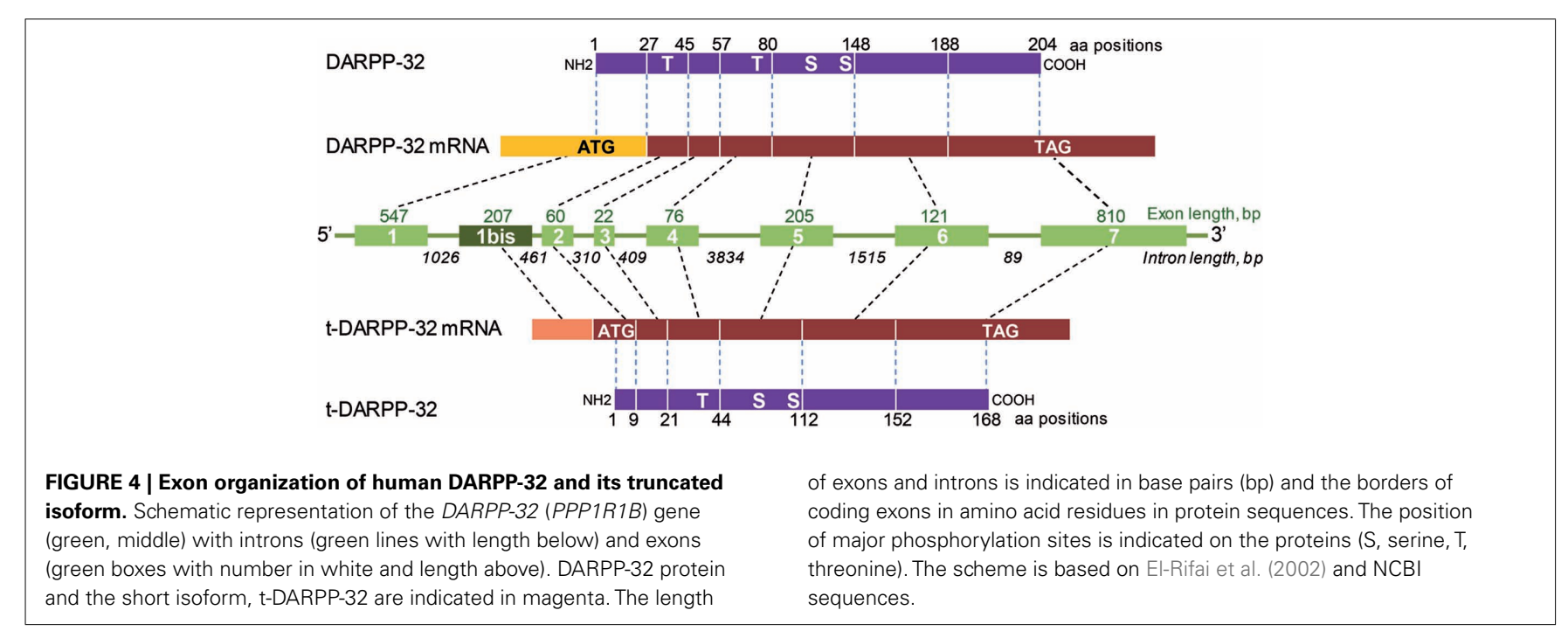


Accordingly the use of a variety of sophisticated mouse models has shown that DARPP-32 mutations do not appear to have severe consequences on spontaneous behavior in laboratory conditions. In contrast these mutations alter the effects of a large number of therapeutic and abused drugs, which represent pharmacological challenges. Similarly, so far no mutation of DARPP-32 has been clearly associated with a human pathology. However, convergent evidence in mice and human suggests that DARPP-32 may be associated with general cognitive performance (Meyer-Lindenberg et al., 2007; Kolata et al., 2010). Thus, the intricate regulations provided by a regulatory molecule such as DARPP-32 may have been selected during vertebrate evolution to optimize brain functions without being absolutely necessary for any of them. It is interesting that the PPP1R1/DARPP-32 family of PP1 inhibitors seems to have originated in early Gnathostomes. This latter type of vertebrates arguably display a more complex behavioral repertoire than jawless animals (Agnathans) and PP1 inhibitors may have contributed to this evolution. In humans, DARPP-32 polymorphisms have been linked to personality traits and could predispose to

\section{REFERENCES}

Ahn, J. H., McAvoy, T., Rakhilin, S. V., Nishi, A., Greengard, P., and Nairn, A. C. (2007a). Protein kinase A activates protein phosphatase $2 \mathrm{~A}$ by phosphorylation of the B56delta subunit. Proc. Natl. Acad. Sci. U.S.A. 104, 2979.

Ahn, J. H., Sung, J. Y., McAvoy, T., Nishi, A., Janssens, V., Goris, J., Greengard, P., and Nairn, A. C. (2007b). The B'/PR72 subunit mediates $\mathrm{Ca} 2+$-dependent dephosphorylation of DARPP-32 by protein phosphatase 2A. Proc. Natl. Acad. Sci. U.S.A. 104, 9876.

Aitken, A., Bilham, T., and Cohen, P. (1982). Complete primary structure of protein phosphatase inhibitor-1 from rabbit skeletal muscle. Eur. J. Biochem. 126, 235-246.

Albert, K. A., Hugh, C, J. H., Adamo, A. I. B., Potkin, S. G., Akbarian, S., Sandman, C. A., Cotman, C. W., William, E. J. B., and Greengard, P. (2002). Evidence for decreased DARPP-32 in the prefrontal cortex of patients with schizophrenia. Arch. Gen. Psychiatry 59, 705-712.

Baracskay, K. L., Haroutunian, V., and Meador-Woodruff, J. H. (2006). Dopamine receptor signaling molecules are altered in elderly schizophrenic cortex. Synapse 60, 271-279.

Barbano, P. E., Spivak, M., Flajolet, M., Nairn, A. C., Greengard, P., and Greengard, L. (2007). A mathematical tool for exploring the dynamics of biological networks. Proc. Natl. Acad. Sci. U.S.A. 104, 19169-19174.

Bateup, H. S., Santini, E., Shen, W., Birnbaum, S., Valjent, E., Surmeier, D. J., gard, P. (2010). Distinct subclasses of medium spiny neurons differentially regulate striatal motor behaviors. Proc. Natl. Acad. Sci. U.S.A. 107, 14845-14850.

Bateup, H. S., Svenningsson, P., Kuroiwa, M., Gong, S., Nishi, A., Heintz, N., and Greengard, P. (2008). Cell type-specific regulation of DARPP-32 phosphorylation by psychostimulant and antipsychotic drugs. Nat. Neurosci. 11, 932-939.

Beaulieu, J. M., Sotnikova, T. D., Marion, S., Lefkowitz, R. J., Gainetdinov, R. R., and Caron, M. G. (2005). An Akt/beta-arrestin 2/PP2A signaling complex mediates dopaminergic neurotransmission and behavior. Cell 122, 261-273.

Belkhiri, A., Dar, A. A., Zaika, A., Kelley, M., and El-Rifai, W. (2008). tDarpp promotes cancer cell survival by up-regulation of $\mathrm{Bcl} 2$ through Akt-dependent mechanism. Cancer Res. 68, 395-403.

Benderska, N., Becker, K., Girault, J. A., Becker, C. M., Andreadis, A., and Stamm, S. (2010). DARPP-32 binds to tra2-betal and influences alternative splicing. Biochim. Biophys. Acta 1799, 448-453.

Berger, B., Febvret, A., Greengard, P., and Goldman-Rakic, P. S. (1990). DARPP-32, a phosphoprotein enriched in dopaminoceptive neurons bearing dopamine D1 receptors: distribution in the cerebral cortex of the newborn and adult rhesus monkey. J. Comp. Neurol.299, 327-348.

Bertran-Gonzalez, J., Bosch, C., Maroteaux, M., Matamales, M.,
Fisone, G., Nestler, E. J., and Green-

psychopathological states. Thus, DARPP-32 is, in principle, an interesting target for pharmacological interventions, with possibilities for enhancing or preventing modulatory functions without altering vital mechanisms. Yet, the molecular properties of DARPP-32, mostly an unstructured protein, do not provide simple binding sites for small molecules making the design of efficient drugs a challenging task. Alteration of its level of expression through gene targeting may be a better way to exert therapeutic effects not only in neuropsychiatry, but also in cancer.

\section{ACKNOWLEDGMENTS}

Work in Jean-Antoine Girault's laboratory is supported by INSERM and UPMC and by grants from the Fondation pour la recherche médicale (FRM), the Agence Nationale de la Recherche (ANR), the Fondation pour la Recherche sur le cerveau (FRC), and the European Research Council (ERC). The group is affiliated to the Ecole des Neurosciences de Paris Ile de France (ENP). Marion Yger is currently supported by the Fondation pour la recherche médicale.

Herve, D., Valjent, E., and Girault, J. A. (2008). Opposing patterns of signaling activation in dopamine D1 and D2 receptor-expressing striatal neurons in response to cocaine and haloperidol. J. Neurosci. 28, 5671-5685.

Bertran-Gonzalez, J., Herve, D., Girault, J. A., and Valjent, E. (2010). What is the degree of segregation between striatonigral and striatopallidal projections? Front. Neuroanat. 4:136. doi: 10.3389/fnana.2010.00136

Beuten, J., Ma, J. Z., Lou, X.-Y., Payne, T. J., and Li, M. D. (2007). Association analysis of the protein phosphatase 1 regulatory subunit $1 \mathrm{~B}$ (PPP1R1B) gene with nicotine dependence in European- and African-American smokers. Am. J. Med. Genet. B 144B, 285-290.

Bibb, J. A., Chen, J., Taylor, J. R., Svenningsson, P., Nishi, A., Snyder, G. L., Yan, Z., Sagawa, Z. K., Ouimet, C. C., Nairn, A. C., Nestler, E. J., and Greengard, P. (2001). Effects of chronic exposure to cocaine are regulated by the neuronal protein Cdk5. Nature 410, 376-380.

Bibb, J. A., Snyder, G. L., Nishi, A., Yan, Z., Meijer, L., Fienberg, A. A., Tsai, L. H., Kwon, Y. T., Girault, J. A., Czernik, A. J., Huganir, R. L., Hemmings, H. C. Jr., Nairn, A. C., and Greengard, P. (1999). Phosphorylation of DARPP-32 by Cdk5 modulates dopamine signalling in neurons. Nature 402, 669-671.

Bollen, M., Peti, W., Ragusa, M. J., and Beullens, M. (2010). The extended PP1 toolkit: designed to create specificity. Trends Biochem. Sci. 35, 450-458.
Bondy, B. (2011). Genetics in psychiatry: are the promises met? World J. Biol. Psychiatry 12, 81-88.

Borgkvist, A., Usiello, A., Greengard, P., and Fisone, G. (2007). Activation of the cAMP/PKA/DARPP-32 signaling pathway is required for morphine psychomotor stimulation but not for morphine reward. Neuropsychopharmacology 32, 1995-2003.

Brené, S., Lindefors, N., Ehrlich, M. Taubes, T., Horiuchi, A., Kopp, J., Hall, H., Sedvall, G., Greengard, P., and Persson, H. (1994). Expression of mRNAs encoding ARPP16/19, ARPP-21, and DARPP- 32 in human brain tissue. J. Neurosci. 14, 985-998.

Bromberg-Martin, E. S., Matsumoto, M., and Hikosaka, O. (2010). Dopamine in motivational control: rewarding, aversive, and alerting. Neuron 68, 815-834.

Brown, A. M., Deutch, A. Y., and Colbran, R. J. (2005). Dopamine depletion alters phosphorylation of striatal proteins in a model of Parkinsonism. Eur. J. Neurosci. 22, 247-256.

Cenci, M. A. (2007). Dopamine dysregulation of movement control in L-DOPA-induced dyskinesia. Trends Neurosci. 30, 236-243.

Colantuoni, C., Hyde, T. M., Mitkus, S., Joseph, A., Sartorius, L., Aguirre, C., Creswell, J., Johnson, E., DeepSoboslay, A., Herman, M. M., Lipska, B. K., Weinberger, D. R., and Kleinman, J. E. (2008). Agerelated changes in the expression of schizophrenia susceptibility genes in the human prefrontal cortex. Brain Struct. Funct. 213, 255-271. 
Corvol, J. C., Studler, J. M., Schonn, J. S., Girault, J. A., and Herve, D. (2001). Galpha(olf) is necessary for coupling D1 and A2a receptors to adenylyl cyclase in the striatum. J. Neurochem. 76, 1585-1588.

Dancheck, B., Nairn, A. C., and Peti, W. (2008). Detailed structural characterization of unbound protein phosphatase 1 inhibitors. Biochemistry 47, 12346-12356.

Darmopil, S., Martin, A. B., De Diego, I. R., Ares, S., and Moratalla, R. (2009). Genetic inactivation of dopamine D1 but not D2 receptors inhibits LDOPA-induced dyskinesia and histone activation. Biol. Psychiatry 66, 603-613.

Desdouits, F., Cheetham, J. J., Huang, H.-B., Kwon, Y.-G., Da Cruz e Silva, E. F., Denefle, P., Ehrlich, M. E., Nairn, A. C., Greengard, P., and Girault, J. A. (1995a). Mechanism of inhibition of protein phosphatase 1 by DARPP- 32: studies with recombinant DARPP-32 and synthetic peptides. Biochem. Biophys. Res. Commun. 206, 652-658.

Desdouits, F., Cohen, D., Nairn, A. C., Greengard, P., and Girault, J. A. (1995b). Phosphorylation of DARPP-32, a dopamine- and CAMPregulated phosphoprotein, by casein kinase I in vitro and in vivo. J. Biol. Chem. 270, 8772-8778.

Desdouits, F., Siciliano, J. C., Greengard, P., and Girault, J. A. (1995c). Dopamine- and cAMP-regulated phosphoprotein DARPP-32: phosphorylation of Ser-137 by casein kinase I inhibits dephosphorylation of Thr-34 by calcineurin. Proc. Natl. Acad. Sci. U.S.A. 92, 2682-2685.

Desdouits, F., Siciliano, J. C., Nairn, A. C., Greengard, P., and Girault, J. A. (1998). Dephosphorylation of Ser137 in DARPP-32 by protein phosphatases 2A and 2C: different roles in vitro and in striatonigral neurons. Biochem. J. 330, 211.

Di Chiara, G. (1999). Drug addiction as dopamine-dependent associative learning disorder. Eur. J. Pharmacol. 375, 13-30.

Egloff, M. P., Johnson, D. F., Moorhead, G., Cohen, P. T. W., Cohen, P., and Barford, D. (1997). Structural basis for the recognition of regulatory subunits by the catalytic subunit of protein phosphatase 1. EMBO J. 16, 1876-1887.

Ehrlich, M. E., Rosen, N. L., Kurihara, T., Shalaby, I. A., and Greengard, P. (1990). DARPP-32 development in the caudate nucleus is independent of afferent input from the substantia nigra. Dev. Brain Res. 54, 257-263.

El-Rifai, W. e., Michael F, J. S., Li, G., Beckler, A., Carl, V. S., Montgomery,
E., Knuutila, S., Moskaluk, C. A., Henry F, J. F., and Powell, S. M. (2002). Gastric cancers overexpress DARPP-32 and a novel isoform, $\mathrm{t}$ DARPP. Cancer Res. 62, 4061-4064.

Feldcamp, L. A., Souza, R. P., RomanoSilva, M., Kennedy, J. L., and Wong, A. H. (2008). Reduced prefrontal cortex DARPP-32 mRNA in completed suicide victims with schizophrenia. Schizophr. Res. 103, 192-200.

Fernandez, E., Schiappa, R., Girault, J. A., and Novère, N. L. (2006). DARPP-32 is a robust integrator of dopamine and glutamate signals. PLoS Comput. Biol. 2, e176. doi: 10.1371/journal.pcbi.0020176

Fienberg, A. A., Hiroi, N., Mermelstein, P. G., Song, W. J., Snyder, G. L., Nishi, A., Cheramy, A., O'Callaghan, J. P., Miller, D. B., Cole, D. G., Corbett, R., Haile, C. N., Cooper, D. C., Onn, S. P., Grace, A. A., Ouimet, C. C., White, F. J., Hyman, S. E., Surmeier, D. J., Girault, J. A., Nestler, E. J., and Greengard, P. (1998). DARPP-32: Regulator of the efficacy of dopaminergic neurotransmission. Science 281, 838-839.

Fischer, E. H. (1997). Cellular regulation by protein phosphorylation: a historical overview. Biofactors 6, 367-374.

Gaspar, P., Bloch, B., and Moine, C. L. (1995). D1 and D2 receptor gene expression in the rat frontal cortex: cellular localization in different classes of efferent neurons. Eur. J. Neurosci. 7, 1050-1063.

Gerfen, C. R., Engber, T. M., Mahan, L. C., Susel, Z., Chase, T. N., Monsma, F. J. Jr., and Sibley, D. R. (1990). D1 and D2 dopamine receptorregulated gene expression of striatonigral and striatopallidal neurons. Science 250, 1429-1432.

Gerfen, C. R., Paletzki, R., and Worley, P. (2008). Differences between dorsal and ventral striatum in Drdla dopamine receptor coupling of dopamine- and cAMP-regulated phosphoprotein-32 to activation of extracellular signal-regulated kinase. J. Neurosci. 28, 7113-7120.

Gharbi-Ayachi, A., Labbe, J. C., Burgess, A., Vigneron, S., Strub, J. M., Brioudes, E., Van-Dorsselaer, A. Castro, A., and Lorca, T. (2010). The substrate of Greatwall kinase, Arpp19, controls mitosis by inhibiting protein phosphatase 2A. Science 330, 1673-1677.

Giorguieff Chesselet, M. F., Kemel, M. L., Wandscheer, D., and Glowinski, J. (1979). Regulation of dopamine release by presynaptic nicotinic receptors in rat striatal slices: effect of nicotine in a low concentration. Life. Sci. 25, 1257-1262.

Girault, J. A., and Greengard, P. (2004) The neurobiology of dopamine signaling. Arch. Neurol. 61, 641-644.

Girault, J. A., Hemmings, H. C. Jr., Williams, K. R., Nairn, A. C., and Greengard, P. (1989a). Phosphorylation of DARPP-32, a dopamineand cAMP-regulated phosphoprotein, by casein kinase II. J. Biol. Chem. 264, 21748-21759.

Girault, J. A., Raisman-Vozari, R., Agid Y., and Greengard, P. (1989b). Striatal phosphoproteins in Parkinson disease and progressive supranuclear palsy. Proc. Natl. Acad. Sci. U.S.A. 86 , 2493-2497.

Girault, J. A., Horiuchi, A., Gustafson, E. L., Rosen, N. L., and Greengard, P. (1990). Differential expression of ARPP-16 and ARPP-19, two highly related cAMP-regulated phosphoproteins, one of which is specifically associated with dopamineinnervated brain regions. J. Neurosci. 10, 1124-1133.

Goldman-Rakic, P. S., Muly, E. C. III and Williams, G. V. (2000). D(1) receptors in prefrontal cells and circuits. Brain Res. Brain Res. Rev. 31 , 295-301.

Grebb, J. A., Girault, J. A., Ehrlich, M. and Greengard, P. (1990). Chronic treatment of rats with SCH-23390 or raclopride does not affect the concentrations of DARPP-32 or its mRNA in dopamine-innervated brain regions. J. Neurochem. 55, 204-207.

Greengard, P. (2001). The neurobiology of slow synaptic transmission. Science 294, 1024-1030.

Greengard, P., Allen, P. B., and Nairn, A. C. (1999). Beyond the dopamine receptor: the DARPP32/protein phosphatase-1 cascade. Neuron 23, 435-447.

Gu, L., Waliany, S., and Kane, S. E. (2009). Darpp-32 and its truncated variant t-Darpp have antagonistic effects on breast cancer cell growth and herceptin resistance. PLOS ONE 4, e6220. doi: 10.1371/journal.pone.0006220

Guitart, X., and Nestler, E. J. (1992). Chronic administration of lithium or other antidepressants increases levels of DARPP-32 in rat frontal cortex. J. Neurochem. 59, 1164-1167.

Halpain, S., Girault, J. A., and Greengard, P. (1990). Activation of NMDA receptors induces dephosphorylation of DARPP-32 in rat striatal slices. Nature 343, 369-372.

Hamada, M., Hendrick, J. P., Ryan, G. R., Kuroiwa, M., Higashi, H., Tanaka, M., Nairn, A. C., Greengard, P., and Nishi, A. (2005). Nicotine regulates DARPP-32 (dopamine-and cAMP-regulated phosphoprotein of $32 \mathrm{kDa})$ phosphorylation at multiple sites in neostriatal neurons. $J$ Pharmacol. Exp. Ther. 315, 872.

Hamada, M., Higashi, H., Nairn, A. C., Greengard, P., and Nishi, A. (2004). Differential regulation of dopamine D1 and D2 signaling by nicotine in neostriatal neurons. J. Neurochem. 90, 1094-1103.

Hamel, S., Bouchard, A., Ferrario, C., Hassan, S., Aguilar-Mahecha, A., Buchanan, M., Quenneville, L., Miller, W., and Basik, M. (2009). Both t-Darpp and DARPP-32 can cause resistance to trastuzumab in breast cancer cells and are frequently expressed in primary breast cancers. Breast Cancer Res. Treat. 120, 47-57.

Hansen, C., Greengard, P., Nairn, A. C., Andersson, T., and Vogel, W. F. (2006). Phosphorylation of DARPP32 regulates breast cancer cell migration downstream of the receptor tyrosine kinase DDR1. Exp. Cell Res. 312, 4011-4018

Hansen, C., Howlin, J., Tengholm, A., Dyachok, O., Vogel, W. F., Nairn, A C., Greengard, P., and Andersson, T. (2009). Wnt-5a-induced phosphorylation of DARPP-32 inhibits breast cancer cell migration in a CREBdependent manner. J. Biol. Chem. 284, 27533-27543.

Hara, M., Fukui, R., Hieda, E., Kuroiwa M., Bateup, H. S., Kano, T., Greengard, P., and Nishi, A. (2010). Role of adrenoceptors in the regulation of dopamine/DARPP-32 signaling in neostriatal neurons. J. Neurochem. 113, 1046-1059.

Hemmings, H. C. Jr., Girault, J. A., Nairn, A. C., Bertuzzi, G., and Greengard, P. (1992). Distribution of protein phosphatase inhibitor1 in brain and peripheral tissues of various species: comparison with DARPP-32. J. Neurochem. 59, 1053-1061

Hemmings, H. C. Jr., and Greengard, P. (1986). DARPP-32, a dopamine- and adenosine $3^{\prime}: 5^{\prime}$ monophosphate- regulated phosphoprotein: regional, tissue, and phylogenetic distribution. J. Neurosci. 6, 1469-1481.

Hemmings, H. C. Jr., Greengard, P. Tung, H. Y. L., and Cohen, P. (1984a). DARPP-32, a dopamineregulated neuronal phosphoprotein, is a potent inhibitor of protein phosphatase-1. Nature 310, 503-505.

Hemmings, H. C. Jr., Nairn, A. C. and Greengard, P. (1984b). DARPP32, a dopamine- and adenosine 
$3^{\prime}: 5^{\prime}$-monophosphate- regulated neuronal phosphoprotein. II. Comparison of the kinetics of phosphorylation of DARPP-32 and phosphatase inhibitor 1. J. Biol. Chem. 259, 14491-14497.

Hemmings, H. C. Jr., Williams, K. R., Konigsberg, W. H., and Greengard, P. (1984c). DARPP-32, a dopamine- and adenosine $3^{\prime}: 5^{\prime}$ monophosphate- regulated neuronal phosphoprotein. I. Amino acid sequence around the phosphorylated threonine. J. Biol. Chem. 259, 14486-14490.

Hemmings, H. C. Jr., Nairn, A. C., Elliott, J. I., and Greengard, P. (1990). Synthetic peptide analogs of DARPP-32 (Mr 32,000 dopamine- and cAMP-regulated phosphoprotein), an inhibitor of protein phosphatase-1. Phosphorylation, dephosphorylation, and inhibitory activity. J. Biol. Chem. 265, 20369-20376.

Heyser, C. J., Fienberg, A. A., Greengard, P., and Gold, L. H. (2000). DARPP-32 knockout mice exhibit impaired reversal learning in a discriminated operant task. Brain Res. 867, 122-130.

Hiroi, N., Fienberg, A. A., Haile, C. N., Alburges, M., Hanson, G. R., Greengard, P., and Nestler, E. J. (1999). Neuronal and behavioural abnormalities in striatal function in DARPP-32-mutant mice. Eur. J. Neurosci. 11,1114-1118.

Hotte, M., Thuault, S., Lachaise, F., Dineley, K. T., Hemmings, $H$. C., Nairn, A. C., and Jay, T. M. (2006). D1 receptor modulation of memory retrieval performance is associated with changes in pCREB and pDARPP-32 in rat prefrontal cortex. Behav. Brain Res. 171, 127-133.

Hsu, J. Y., Sun, Z. W., Li, X., Reuben, M., Tatchell, K., Bishop, D. K., Grushcow, J. M., Brame, C. J., Caldwell, J. A., Hunt, D. F., Lin, R., Smith, M. M., and Allis, C. D. (2000). Mitotic phosphorylation of histone $\mathrm{H} 3$ is governed by Ipl1/aurora kinase and Glc7/PP1 phosphatase in budding yeast and nematodes. Cell 102, 279-291.

Hu, J. X., Yu, L., Shi, Y. Y., Zhao, X. Z., Meng, J. W., He, G., Xu, Y. F., Feng, G. Y., and He, L. (2007). An association study between PPP1R1B gene and schizophrenia in the Chinese population. Prog. Neuropsychopharmacol. Biol. Psychiatry 31, 1303-1306.

Huang, H., Horiuchi, A., Watanabe, T., Shih, S. R., Tsay, H. J., Li, H. C., Greengard, P., and Nairn, A. C. (1999). Characterization of the inhibition of protein phosphatase-1 by
DARPP-32 and inhibitor-2. J. Biol. Chem. 274, 7870.

Ibba, F., Vinci, S., Spiga, S., Peana, A. T., Assaretti, A. R., Spina, L., Longoni, R., and Acquas, E. (2009). Ethanolinduced extracellular signal regulated kinase: role of dopamine D1 receptors. Alcohol. Clin. Exp. Res. 33, 858-867.

Imperato, A., Mulas, A., and Di Chiara, G. (1986). Nicotine preferentially stimulates dopamine release in the limbic system of freely moving rats. Eur. J. Pharmacol. 132, 337-338.

Ishikawa, M., Mizukami, K., Iwakiri, M., and Asada, T. (2007). Immunohistochemical and immunoblot analysis of Dopamine and cyclic AMPregulated phosphoprotein, relative molecular mass 32,000 (DARPP32 ) in the prefrontal cortex of subjects with schizophrenia and bipolar disorder. Prog. Neuropsychopharmacol. Biol. Psychiatry 31, 1177-1181.

Janssens, V., Longin, S., and Goris, J. (2008). PP2A holoenzyme assembly: in cauda venenum (the sting is in the tail). Trends Biochem. Sci. 33, 113-121.

Jin, M., Bateup, H., Padovan, J. C., Greengard, P., Nairn, A. C., and Chait, B. T. (2005). Quantitative analysis of protein phosphorylation in mouse brain by hypothesis-driven multistage mass spectrometry. Anal. Chem. 77, 7845-7851.

Johansen, K. M., and Johansen, J. (2006). Regulation of chromatin structure by histone H3S10 phosphorylation. Chromosome Res. 14, 393-404.

Kebabian, J. W., Petzold, G. L., and Greengard, P. (1972). Dopaminesensitive adenylate cyclase in caudate nucleus of rat brain, and its similarity to the "dopamine receptor." Proc. Natl. Acad. Sci. U.S.A. 69 , 2145-2149.

King, M. M., Huang, C. Y., Chock, P. B., Nairn, A. C., Hemmings, H. C. Jr., Chan, K. F., and Greengard, P. (1984). Mammalian brain phosphoproteins as substrates for calcineurin. J. Biol. Chem. 259, 8080-8083.

Kolata, S., Light, K., Wass, C. D., ColasZelin, D., Roy, D., and Matzel, L. D. (2010). A dopaminergic gene cluster in the prefrontal cortex predicts performance indicative of general intelligence in genetically heterogeneous mice. PLoS ONE 5, e14036. doi: 10.1371/journal.pone. 0014036

Krueger, B. K., Forn, J., and Greengard, P. (1975). Dopamine-sensitive adenylate cyclase and protein phosphorylation in the rat caudate nucleus. Psychopharmacol. Bull. 11, $10-11$.

Kull, B., Svenningsson, P., and Fredholm, B. B. (2000). Adenosine A(2A) receptors are colocalized with and activate $\mathrm{g}(\mathrm{olf})$ in rat striatum. Mol. Pharmacol. 58, 771-777.

Kunii, Y., Yabe, H., Wada, A., Yang, Q. Nishiura, K., and Niwa, S.-I. (2011). Altered DARPP-32 expression in the superior temporal gyrus in schizophrenia. Prog. Neuropsychopharmacol. Biol. Psychiatry 35, 1139-1143.

Kwon, Y. G., Huang, H. B., Desdouits, F., Girault, J. A., Greengard, P., and Nairn, A. C. (1997). Characterization of the interaction between DARPP-32 and protein phosphatase 1 (PP-1): DARPP-32 peptides antagonize the interaction of PP-1 with binding proteins. Proc. Natl. Acad. Sci. U.S.A. 94, 3536-3541.

Le Novère, N., Li, L., and Girault, J. A. (2008). DARPP-32: molecular integration of phosphorylation potential. Cell. Mol. Life Sci. 65, 2125-2127.

Ledent, C., Vaugeois, J. M., Schiffmann S. N., Pedrazzini, T., El Yacoubi, M. Vanderhaeghen, J. J., Costentin, J., Heath, J. K., Vassart, G., and Parmentier, M. (1997). Aggressiveness, hypoalgesia and high blood pressure in mice lacking the adenosine A2a receptor. Nature 388 674-678.

Lewis, C. M., Levinson, D. F., Wise, L. H., DeLisi, L. E., Straub, R. E., Hovatta, I., Williams, N. M., Schwab, S. G., Pulver, A. E., Faraone, S. V., Brzustowicz, L. M., Kaufmann, C. A., Garver, D. L., Gurling, H. M., Lindholm, E., Coon, H., Moises, H. W., Byerley, W., Shaw, S. H., Mesen, A., Sherrington, R., O'Neill, F. A., Walsh, D., Kendler, K. S. Ekelund, J., Paunio, T., Lonnqvist, J., Peltonen, L., O’Donovan, M. C. Owen, M. J., Wildenauer, D. B. Maier, W., Nestadt, G., Blouin, J. L., Antonarakis, S. E., Mowry, B. J., Silverman, J. M., Crowe, R. R., Cloninger, C. R., Tsuang, M. T., Malaspina, D., Harkavy-Friedman, J. M., Svrakic, D. M., Bassett, A. S. Holcomb, J., Kalsi, G., McQuillin, A., Brynjolfson, J., Sigmundsson, T., Petursson, H., Jazin, E., Zoega, T. and Helgason, T. (2003). Genome scan meta-analysis of schizophrenia and bipolar disorder, part II: schizophrenia. Am. J. Hum. Genet. 73, 34-48.

Li, C. H., Liao, H. M., Hung, T. W., and Chen, C. H. (2006). Mutation analysis of DARPP-32 as a candidate gene for schizophrenia. Schizophr. Res. 87 $1-5$

Li, J., Ma, H., Zhou, H., Huang, Y., Wu, L., Li, J., and $\mathrm{Zhu}$
G. (2011). Association between DARPP-32 gene polymorphism and personality traits in healthy ChineseHan subjects. J. Mol. Neurosci. 44 48-52.

Liedtke, W. B., McKinley, M. J., Walker, L. L., Zhang, H., Pfenning, A. R., Drago, J., Hochendoner, S. J., Hilton, D. L., Lawrence, A. J., and Denton, D. A. (2011). Relation of addiction genes to hypothalamic gene changes subserving genesis and gratification of a classic instinct, sodium appetite. Proc. Natl. Acad. Sci. U.S.A. 108, 12509-12514

Lindskog, M., Kim, M., Wikström, M. A., Blackwell, K. T., and Kotaleski, J. H. (2006). Transient calcium and dopamine increase PKA activity and DARPP-32 phosphorylation. PLoS Comput. Biol. 2, e119. doi: 10.1371/journal.pcbi.0020119

Lindskog, M., Svenningsson, P., Pozzi, L., Kim, Y., Fienberg, A. A., Bibb, J. A., Fredholm, B. B., Nairn, A. C., Greengard, P., and Fisone, G. (2002). Involvement of DARPP32 phosphorylation in the stimulant action of caffeine. Nature 418, 774-778.

Luscher, C., and Malenka, R. C. (2011). Drug-evoked synaptic plasticity in addiction: from molecular changes to circuit remodeling. Neuron 69 , 650-663.

Mani, S. K., Fienberg, A. A., O'Callaghan, J. P., Snyder, G. L., Allen, P. B., Dash, P. K., Moore, A. N., Mitchell, A. J., Bibb, J., Greengard, P., and O'Malley, B. W. (2000). Requirement for DARPP-32 in progesterone-facilitated sexual receptivity in female rats and mice. Science 287, 1053-1056.

Marsh, J. A., Dancheck, B., Ragusa, M. J., Allaire, M., Forman-Kay, J. D., and Peti, W. (2010). Structural diversity in free and bound states of intrinsically disordered protein phosphatase 1 regulators. Structure $18,1094-1103$

Mayerhofer, A., Fritz, S., Mani, S., Rajendra Kumar, T., Thalhammer, A., Ingrassia, P., Fienberg, A. A., and Greengard, P. (2004). Ovarian function and morphology after deletion of the DARPP-32 gene in mice. Exp. Clin. Endocrinol. Diabetes 112, 451-457.

Mayerhofer, A., Hemmings, H. C. Jr., Snyder, G. L., Greengard, P., Boddien, S., Berg, U., and Brucker, C. (1999). Functional dopamine1 receptors and DARPP-32 are expressed in human ovary and granulosa luteal cells in vitro. J. Clin. Endocrinol. Metab. 84, 257-264.

Meister, B., Fryckstedt, J., Schalling, M., Cortes, R., Hokfelt, T., Aperia A., Hemmings, H. C. Jr., Nairn, 
A. C., Ehrlich, M., and Greengard, P. (1989). Dopamine- and cAMPregulated phosphoprotein (DARPP32) and dopamine DAl agonistsensitive $\mathrm{Na}+, \mathrm{K}+$-ATPase in normal tubule cells. Proc. Natl. Acad. Sci. U.S.A. 86, 8068-8072.

Meredith, J. M., Moffatt, C. A., Auger, A. P., Snyder, G. L., Greengard, P., and Blaustein, J. D. (1998). Matingrelated stimulation induces phosphorylation of dopamine- and cyclic AMP-regulated phosphoprotein-32 in progestin receptor-containing areas in the female rat brain. $J$. Neurosci. 18, 10189-10195.

Meyer-Lindenberg, A., Straub, R. E., Lipska, B. K., Verchinski, B. A., Goldberg, T., Callicott, J. H., Egan, M. F., Huffaker, S. S., Mattay, V. S., Kolachana, B., Kleinman, J. E., and Weinberger, D. R. (2007). Genetic evidence implicating DARPP-32 in human frontostriatal structure, function, and cognition. J. Clin. Invest. 117, 672 .

Mink, J. W. (1996). The basal ganglia: focused selection and inhibition of competing motor programs. Prog. Neurobiol. 50, 381-425.

Mochida, S., Maslen, S. L., Skehel, M., and Hunt, T. (2010). Greatwall phosphorylates an inhibitor of protein phosphatase $2 \mathrm{~A}$ that is essential for mitosis. Science 330, 1670-1673.

Moorhead, G. B. G., Trinkle-Mulcahy, L., and Ulke-Lemée, A. (2007). Emerging roles of nuclear protein phosphatases. Nat. Rev. Mol. Cell Biol. 7, 235-244.

Nairn, A. C., Svenningsson, P., Nishi, A., Fisone, G., Girault, J. A., and Greengard, P. (2004). The role of DARPP32 in the actions of drugs of abuse. Neuropharmacology 47(Suppl. 1), 14-23.

Nakano, T., Doi, T., Yoshimoto, J., and Doya, K. (2010). A kinetic model of dopamine- and calciumdependent striatal synaptic plasticity. PLoS Comput. Biol. 6, e1000670. doi: 10.1371/journal.pcbi.1000670

Nei, M., and Kumar, S. (2000). Molecular Evolution and Phylogenetics. New York, NY: Oxford University Press Inc.

Nestler, E. J., and Greengard, P. (1983). Protein phosphorylation in the brain. Nature 305, 583-588.

Neyroz, P., Desdouits, F., Benfenati, F., Knutson, J. R., Greengard, P., and Girault, J. A. (1993). Study of the conformation of DARPP32 , a dopamine- and cAMP- regulated phosphoprotein, by fluorescence spectroscopy. J. Biol. Chem. 268, 24022-24031.

Nishi, A., Bibb, J. A., Matsuyama, S., Hamada, M., Higashi, H., Nairn, A. C., and Greengard, P.
(2002). Regulation of DARPP32 dephosphorylation at PKAand Cdk5-sites by NMDA and AMPA receptors: distinct roles of calcineurin and protein phosphatase-2A. J. Neurochem. 81, 832-841.

Nishi, A., Bibb, J. A., Snyder, G. L., Higashi, H., Nairn, A. C., and Greengard, P. (2000a). Amplification of dopaminergic signaling by a positive feedback loop. Proc. Natl. Acad. Sci. U.S.A. 97, 12840.

Nishi, A., Bibb, J. A., Snyder, G. L., Higashi, H., Nairn, A. C., and Greengard, P. (2000b). Amplification of dopaminergic signaling by a positive feedback loop. Proc. Natl. Acad. Sci. U.S.A. 97, 12840-12845.

Nishi, A., Snyder, G. L., Nairn, A. C., and Greengard, P. (1999). Role of calcineurin and protein phosphatase$2 \mathrm{~A}$ in the regulation of DARPP32 dephosphorylation in neostriatal neurons. J. Neurochem. 72, 2015-2021.

Ouimet, C. C. (1991). DARPP-32, a dopamine and cyclic AMP-regulated phosphoprotein, is present in corticothalamic neurons of the rat cingulate cortex. Brain Res. 562, 85-92.

Ouimet, C. C., da Cruz e Silva, E. F., and Greengard, P. (1995). The alpha and gamma 1 isoforms of protein phosphatase 1 are highly and specifically concentrated in dendritic spines. Proc. Natl. Acad. Sci. U.S.A. 92, 3396-3400.

Ouimet, C. C., and Greengard, P. (1990). Distribution of DARPP-32 in the basal ganglia: an electron microscopic study. J. Neurocytol. 19 , 39-52.

Ouimet, C. C., Langley-Gullion, K. C., and Greengard, P. (1998). Quantitative immunocytochemistry of DARPP-32-expressing neurons in the rat caudatoputamen. Brain Res. 808, 8-12.

Ouimet, C. C., Miller, P. E., Hemmings, H. C., Walaas, S. I., and Greengard, P. (1984). DARPP-32, a dopamine-and adenosine $3^{\prime}$ : 5'-monophosphateregulated phosphoprotein enriched in dopamine-innervated brain regions. III. Immunocytochemical localization. J. Neurosci. 4, 111.

Pascoli, V., Besnard, A., Herve, D., Pages, C., Heck, N., Girault, J. A., Caboche, J., and Vanhoutte, P. (2011). Cyclic adenosine monophosphateindependent tyrosine phosphorylation of NR2B mediates cocaineinduced extracellular signalregulated kinase activation. Biol. Psychiatry 69, 218-227.

Qi, Z., Miller, G. W., and Voit, E. O. (2010). The internal state of medium spiny neurons varies in response to different input signals. BMC Syst. Biol. 4, 26. PMID:20236543

Raisman-Vozari, R., Girault, J. A., Moussaoui, S., Feuerstein, C., Jenner, P., Marsden, C. D., and Agid Y. (1990). Lack of change in striatal DARPP-32 levels following nigrostriatal dopaminergic lesions in animals and in parkinsonian syndromes in man. Brain Res. 507, 45-50.

Redgrave, P., Prescott, T. J., and Gurney, K. (1999). The basal ganglia: a vertebrate solution to the selection problem? Neuroscience 89 , 1009-1023.

Reuter, M., Weber, B., Fiebach, C. J., Elger, C., and Montag, C. (2009). The biological basis of anger: associations with the gene coding for DARPP-32 (PPP1R1B) and with amygdala volume. Behav. Brain Res. 202, 179-183.

Saitou, N., and Nei, M. (1987). The neighbor-joining method: a new method for reconstructing phylogenetic trees. Mol. Biol. Evol. 4, 406-425.

Santini, E., Alcacer, C., Cacciatore, S. Heiman, M., Herve, D., Greengard P., Girault, J. A., Valjent, E., and Fisone, G. (2009). L-DOPA activates ERK signaling and phosphorylates histone $\mathrm{H} 3$ in the striatonigral medium spiny neurons of hemiparkinsonian mice. J. Neurochem. 108, 621-633.

Santini, E., Valjent, E., Usiello, A. Carta, M., Borgkvist, A., Girault J. A., Herve, D., Greengard, P., and Fisone, G. (2007). Critical involvement of cAMP/DARPP-32 and extracellular signal-regulated protein kinase signaling in L-DOPAinduced dyskinesia. J. Neurosci. 27, 6995-7005.

Satel, S. (2006). Is caffeine addictive? - a review of the literature. Am. J. Drug Alcohol Abuse 32, 493-502.

Schultz, W. (2002). Getting formal with dopamine and reward. Neuron 36 241-263.

Souza, B. R., Motta, B. S., Rosa, D. V., Torres, K. C., Castro, A. A., Comim, C. M., Sampaio, A. M. Lima, F. F., Jeromin, A., Quevedo, J., and Romano-Silva, M. A. (2008). DARPP-32 and NCS-1 expression is not altered in brains of rats treated with typical or atypical antipsychotics. Neurochem. Res. 33 533-538.

Stipanovich, A., Valjent, E., Matamales, M., Nishi, A., Ahn, J. H., Maroteaux M., Bertran-Gonzalez, J., BramiCherrier, K., Enslen, H., Corbille, A. G., Filhol, O., Nairn, A. C., Greengard, l., Herve, D., and Girault, J. A. (2008). A phosphatase cascade by which rewarding stimuli control nucleosomal response. Nature 453, 879-884.

Sutherland, E. W. (1972). Studies on the mechanism of hormone action. Science 177, 401-408.

Svenningsson, P., Lindskog, M., Ledent, C., Parmentier, M., Greengard, P. Fredholm, B. B., and Fisone, G. (2000). Regulation of the phosphorylation of the dopamine- and cAMP-regulated phosphoprotein of $32 \mathrm{kDa}$ in vivo by dopamine $\mathrm{D} 1$ dopamine D2, and adenosine A2A receptors. Proc. Natl. Acad. Sci. U.S.A. 97, 1856-1860.

Svenningsson, P., Nishi, A., Fisone, G., Girault, J.-A., Nairn, A. C., and Greengard, P. (2004). DARPP-32: an integrator of neurotransmission. Annu. Rev. Pharmacol. Toxicol. 44, 269-296.

Svenningsson, P., Tzavara, E., Carruthers, R., Rachleff, I., Wattler, S., Nehls, M., McKinzie, D. L., Fienberg, A. A., Nomikos, G. G., and Greengard, P. (2003). Diverse psychotomimetics act through a common signaling pathway. Science 302, 1412-1415.

Svenningsson, P., Tzavara, E. T., Liu, F., Fienberg, A. A., Nomikos, G. G., and Greengard, P. (2002a) DARPP-32 mediates serotonergic neurotransmission in the forebrain. Proc. Natl. Acad. Sci. U.S.A. 99, 3188-3193.

Svenningsson, P., Tzavara, E. T., Witkin, J. M., Fienberg, A. A., Nomikos, G. G., and Greengard, P. (2002b) Involvement of striatal and extrastriatal DARPP-32 in biochemical and behavioral effects of fluoxetine (Prozac). Proc. Natl. Acad. Sci. U.S.A 99, 3182-3187.

Tamura, K., Peterson, D., Peterson, N., Stecher, G., Nei, M., and Kumar, S. (2011). MEGA5: molecular evolutionary genetics analysis using maximum likelihood, evolutionary distance, and maximum parsimony methods. Mol. Biol. Evol. doi: 10.1093/molbev/msr121. [Epub ahead of print].

Tepper, J. M., and Bolam, J. P. (2004). Functional diversity and specificity of neostriatal interneurons. Curr. Opin. Neurobiol. 14, 685-692.

Torres, K. C., Souza, B. R., Miranda, D. M., Nicolato, R., Neves, F. S. Barros, A. G., Dutra, W. O., Gollob, K. J., Correa, H., and RomanoSilva, M. A. (2009). The leukocytes expressing DARPP-32 are reduced in patients with schizophrenia and bipolar disorder. Prog. Neuropsychopharmacol. Biol. Psychiatry 33, 214-219.

Valjent, E., Bertran-Gonzalez, J., Aubier, B., Greengard, P., Herve, D., and Girault, J. A. (2010). Mechanisms of 
locomotor sensitization to drugs of abuse in a two-injection protocol. Neuropsychopharmacology 35, 401-415.

Valjent, E., Bertran-Gonzalez, J., Herve, D., Fisone, G., and Girault, J. A. (2009). Looking BAC at striatal signaling: cell-specific analysis in new transgenic mice. Trends Neurosci. 32, 538-547.

Valjent, E., Corvol, J. C., Pages, C., Besson, M. J., Maldonado, R., and Caboche, J. (2000). Involvement of the extracellular signalregulated kinase cascade for cocainerewarding properties. J. Neurosci. 20, 8701-8709.

Valjent, E., Pages, C., Herve, D., Girault, J. A., and Caboche, J. (2004). Addictive and non-addictive drugs induce distinct and specific patterns of ERK activation in mouse brain. Eur. J. Neurosci. 19, 1826-1836.

Valjent, E., Pascoli, V., Svenningsson, P., Paul, S., Enslen, H., Corvol, J. C., Stipanovich, A., Caboche, J., Lombroso, P. J., Nairn, A. C., Greengard, P., Hervé, D., and Girault, J. A. (2005). Regulation of a protein phosphatase cascade allows convergent dopamine and glutamate signals to activate ERK in the striatum. Proc. Natl. Acad. Sci. U.S.A. 102, 491.

Vanderschuren, L. J., Schmidt, E. D., De Vries, T. J., Van Moorsel, C. A., Tilders, F. J., and Schoffelmeer, A. N. (1999). A single exposure to amphetamine is sufficient to induce long-term behavioral, neuroendocrine, and neurochemical sensitization in rats. J. Neurosci. 19, 9579-9586.

Vangamudi, B., Peng, D. F., Cai, Q., El-Rifai, W., Zheng, W., and Belkhiri, A. (2010). t-DARPP regulates phosphatidylinositol-3-kinasedependent cell growth in breast cancer. Mol. Cancer 9, 240.

Vangamudi, B., Zhu, S., Soutto, M., Belkhiri, A., and El-Rifai, W. (2011). Regulation of beta-catenin by $\mathrm{t}$ DARPP in upper gastrointestinal cancer cells. Mol. Cancer 10,32 .

Vezina, P., and Leyton, M. (2009). Conditioned cues and the expression of stimulant sensitization in animals and humans. Neuropharmacology 56(Suppl. 1), 160-168.

Walaas, S. I., Aswad, D. W., and Greengard, P. (1983a). A dopamineand cyclic AMP-regulated phosphoprotein enriched in dopamineinnervated brain regions. Nature 301, 69-71.

Walaas, S. I., Nairn, A. C., and Greengard, P. (1983b). Regional distribution of calcium- and cyclic adenosine $\quad 3^{\prime}: 5^{\prime}$-monophosphateregulated protein phosphorylation systems in mammalian brain. II Soluble systems. J. Neurosci. 3, 302-311.

Walsh, D. A., Perkins, J. P., and Krebs, E. G. (1968). An adenosine $3^{\prime}, 5^{\prime}$ monophosphate-dependant protein kinase from rabbit skeletal muscle. $J$. Biol. Chem. 243, 3763-3765.

Wang, X., Liu, B., Li, N., Li, H., Qiu, J., Zhang, Y., and Cao, X. (2008). IPP5, a novel protein inhibitor of protein phosphatase 1, promotes G1/S progression in a Thr-40-dependent manner. J. Biol. Chem. 283 12076-12084.

Wise, R. A. (1987). The role of reward pathways in the development of drug dependence. Pharmacol. Ther. 35, 227-263.

Yoshimi, A., Takahashi, N., Saito, S., Ito Y., Aleksic, B., Usui, H., Kawamura, Y., Waki, Y., Yoshikawa, T., Kato, T., Iwata, N., Inada, T., Noda, Y., and Ozaki, N. (2008). Genetic analysis of the gene coding for DARPP-32 (PPP1R1B) in Japanese patients with schizophrenia or bipolar disorder. Schizophr. Res. 100, 334-341.

Zachariou, V., Benoit-Marand, M. Allen, P. B., Ingrassia, P., Fienberg, A. A., Gonon, F., Greengard, P., and Picciotto, M. R. (2002). Reduction of cocaine place preference in mice lacking the protein phosphatase 1 inhibitors DARPP 32 or inhibitor 1 . Biol. Psychiatry 51, 612-620.

Zachariou, V., Sgambato-Faure, V., Sasaki, T., Svenningsson, P., Berton, O., Fienberg, A. A., Nairn, A. C. Greengard, P., and Nestler, E. J. (2006). Phosphorylation of DARPP32 at Threonine-34 is required for cocaine action. Neuropsychopharmacology 31, 555-562.

Zhan, L., Kerr, J. R., Lafuente, M. J., Maclean, A., Chibalina, M. V., Liu, B., Burke, B., Bevan, S., and Nasir, J. (2010). Altered expression and coregulation of dopamine signalling genes in schizophrenia and bipolar disorder. Neuropathol. Appl. Neurobiol. 37, 206-219.

Zhang, Y., Svenningsson, P., Picetti, R., Schlussman, S. D., Nairn, A. C., Ho, A., Greengard, P., and Kreek, M. J. (2006). Cocaine self-administration in mice is inversely related to phosphorylation at Thr34 (protein kinase A site) and Ser130 (kinase CK1 site) of DARPP-32. J. Neurosci. 26, 2645-2651.

Zhu, H., Lee, M., Guan, F., Agatsuma, S., Scott, D., Fabrizio, K., Fienberg, A. A., and Hiroi, N. (2005). DARPP-32 phosphorylation opposes the behavioral effects of nicotine. Biol. Psychiatry 58, 981-989.

Conflict of Interest Statement: The authors declare that the research was conducted in the absence of any commercial or financial relationships that could be construed as a potential conflict of interest.

Received: 16 July 2011; accepted: 16 August 2011; published online: 08 September 2011.

Citation: Yger M and Girault J-A (2011) DARPP-32, jack of all trades. . . master of which? Front. Behav. Neurosci. 5:56. doi: 10.3389/fnbeh.2011.00056

Copyright (C) 2011 Yger and Girault. This is an open-access article subject to a nonexclusive license between the authors and Frontiers Media SA, which permits use, distribution and reproduction in other forums, provided the original authors and source are credited and other Frontiers conditions are complied with. 